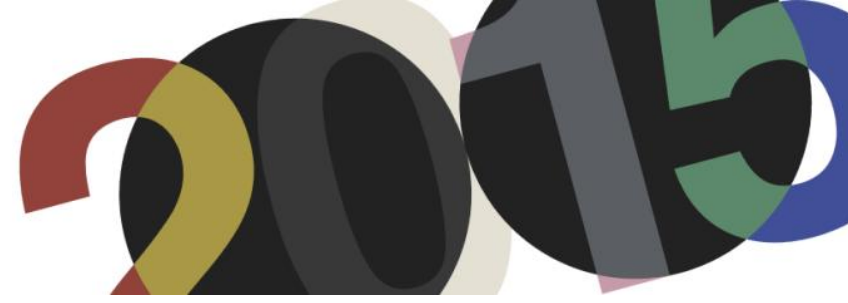

DOI: http://dx.doi.org/10.4995/LC2015.2015.758

\title{
Le Corbusier y Lilette Ripert. Les Maternelles vous parlent, hacia una pedagogía más humana
}

\author{
P. Lacomba Montes
}

Escuela Técnica Superior de Arquitectura de Valencia

\begin{abstract}
Resumen: La escuela de l'Unité d'habitation de Marseille se desarrolló a lo largo de más de una década. Los primeros dibujos realizados por Le Corbusier datan de 1944 y surgen varias evoluciones del proyecto hasta alcanzar la propuesta que finalmente se ejecuta en 1953. Durante este periodo surge la voluntad de atender a los principios pedagógicos de Céléstin Freinet de l'Ecole Moderne que estudiará y aplicará en la arquitectura que propone. Las técnicas planteadas por Freinet se desarrollaron en el centro de l'Unité por Lilette Ripert, una ferviente admiradora de Le Corbusier y colaboradora de Freinet, que reflejará en sus escritos, cartas, poemas y dibujos la capacidad de entender la escuela desde su uso. Se trata de una arquitectura que se desarrolla en paralelo a un sistema educativo y tiene la gran capacidad de adaptarse a los cambios que se proponen y seguir teniendo unos espacios docentes de calidad. Es una arquitectura hecha para sus usuarios y que permanece viva a pesar del paso del tiempo.
\end{abstract}

Abstract: The school of l'Unité d'habitation de Marseille developed over more than a decade. The first drawings date back to 1944 and emerge several project proposals until the final one is reached by 1953. During this process Le Corbusier came across with Céléstin Freinet's pedagogical principles and decided to study and apply them in his architecture. These techniques promoted by Freinet were lately developed in the school by Lilette Ripert, a fervent admirer of Le Corbusier and contributor of Freinet. She was able to understand the school from its use, and showed it in her writings, drawings, letters and poems. The project finally built develops in parallel to the educational system and has the ability to adapt to all changes without losing its spatial qualities. It is indeed a piece of work done with and for its users. Despite the passage of time, it is still alive.

Palabras clave: Les Maternelles; Lilette Ripert; Céléstin Freinet; pedagogy; childhood; Le Corbusier. Keywords: Les Maternelles; Lilette Ripert; Céléstin Freinet; pedagogía; infancia; Le Corbusier.

\section{Introducción}

La construcción de la escuela "Les Maternelles Marseille-Michelet" en la década de los 50 y el éxito de su funcionamiento durante varias décadas se debió a la implicación y dedicación de personajes procedentes de varias disciplinas. Fueron estas relaciones interdisciplinares las que enriquecieron tanto el proceso de elaboración del proyecto como el uso que se hizo de la escuela durante los años posteriores. La correspondencia mantenida entre Le Corbusier y el pedagogo francés Céléstin Freinet (1896-1966) durante el año 1950 refleja ese primer intercambio de intenciones, tratando de introducir los principios de una educación renovadora conocida como l'École Moderne. Posteriormente, la investigación se centra en la correspondencia entre Lilette Ougier (Ripert, N.D.E) (1918-2000) primera institutriz de la escuela, y Le Corbusier y en el legado de Lilette Ripert. A partir de ahí se explica la escuela que Le Corbusier propuso, atendiendo a los principios educativos planteados por Freinet y a través de la correspondencia y los documentos generados en la escuela como muestras de la relación mantenida entre el arquitecto y la primera institutriz. Son ellos los que manifiestan el mayor logro de la escuela: el florecimiento compartido de una pedagogía más humana. El objetivo del trabajo es hacer una reflexión exhaustiva de la escuela sobre la cubierta del edificio de l'Unité d'habitation de Marseille desde el 
punto de vista de su funcionamiento. Cómo lo construido, el espacio proyectado por Le Corbusier, es un reflejo de los principios pedagógicos de Freinet.

Le Corbusier, como arquitecto responsable de la construcción de un lugar de aprendizaje, establece un primer contacto con Céléstin Freinet poco tiempo antes de la ejecución de la escuela. Este primer intercambio de ideas entre ambos personajes deja constancia de la necesidad de atender a unas bases teóricas ideadas por el pedagogo $\mathrm{y}$, por tanto, de unas necesidades programáticas a las que el arquitecto otorga una respuesta. Lilette Ripert, directora que dirigirá la escuela desde 1953 hasta aproximadamente finales de los años 60, había colaborado con Céléstin Freinet ${ }^{1}$, cuya línea educativa es la base de todas sus actividades de innovación didáctica. Demuestra a través de sus escritos el exitoso desarrollo de su profesión dentro de la escuela y por consiguiente el progreso de los niños. Como muestra de su admiración, Le Corbusier apelaría más tarde a Lilette Ripert para los proyectos de Les Maternelles de otras unités d'habitation.

Entre las fuentes de información utilizadas para desarrollar la investigación se encuentran: las teorías pedagógicas de Freinet (Témoignages), el intercambio inicial de ideas entre Le Corbusier y Céléstin Freinet en 1950 (disponible en la Fondation Le Corbusier), la correspondencia mantenida entre Le Corbusier y Lilette Ripert entre 1953 y 1965 (disponible en la Fondation Le Corbusier), el legado de ambos reflejado en el libro póstumo de Le Corbusier, Les Maternelles vous parlent en 1969, las imágenes tomadas durante aquellos años por Louis Sciarli y Lucien Hervé y los planos y documentación gráfica de la escuela.

\section{Intercambio de ideas entre Le Corbusier y Céléstin Freinet. 1950}

Céléstin Freinet (1896-1966) plasmó en la Escuela Moderna los principios de una educación nueva. Sustentada en una pedagogía activa, popular, abierta, centrada en el trabajo, cooperativista, democrática, participativa y metodológica; persigue un lugar en el que los alumnos unan pensamiento y acción. El libro pretendía potenciar el trabajo de los alumnos en el aula, el cuidado de la huerta y de los animales. Se preocupaba por la renovación del ambiente escolar y de la actitud de los maestros y no sólo por el método o las teorías de su sistema. Maestro y niños debían nutrirse mutuamente, como así escribió en Témoinages: "Ces formes majeures son montées dans un cheminement à peine perceptible, en une continuité de tous les jours, dans ceta atmosphére idéale d'une clase où maître et enfants apportent leur part. ${ }^{2}$ " Su objetivo principal era que el niño piense haciendo y haga pensando.

Las técnicas de Freinet constituyen un abanico de actividades que estimulan el tanteo experimental, la libre expresión infantil, la cooperación y la investigación del entorno. Están pensadas sobre la base funcional de la comunicación. Entre ellas destacan: texto libre, la revista escolar, los planes de trabajo, las conferencias, la biblioteca de trabajo, la asamblea de clase y la correspondencia escolar.

Freinet entendía que sus planteamientos necesitaban un medio adecuado dónde pudieran aplicarse todas sus teorías. Así, en la carta dirigida por Freinet a Le Corbusier el 14 de febrero de 1950, en plena construcción de 1'Unité, escribe: "Il y a trois ans j'avais, par l'intermédiaire de notar Revue L'EDUCATEUR organisé un concours destiné aux architectes pour la réalisation de locaux scolaires répondant aux besoins de notre

\footnotetext{
${ }^{1}$ Cf. Giorgio De Ferrari, "Bambini fanno - a Marsiglia, a Monaco, a Vancouver", in: Domus, n"565, décembre 1976, p. 2627/IV(article certainement autorisé par Lilette Ripert) ; cf. également : Noél Jouenne, Le Corbusier comme compétence. Pratiques sociales dans I'Unité d'Habitation Le Corbusier de Firminy, p.112.

${ }^{2}$ Manifiesto. Témoignages. Elise y Céléstin Freinet. (FLC U1-17 135)
} 
pédagogie. ${ }^{3}$ " Freinet, interesado en establecer ese primer contacto antes de la construcción de Les Maternelles sobre la cubierta de l'Unité d'habitation de Marseille, le transmite esas inquietudes por construir una escuela que responda rigurosamente a sus objetivos: "Nous avons montré pratiquement, experimentalement la nécessité d'une modernisation de notre enseignement, par l'introduction notamment d'outils nouveaux et de techniques aujourd'hui officiellement recommandés: Imprimerie à l'Ecole, Limographe, Journaux Scolaires, Travail libre, Fichiers, Dessin, jardinage, etc... ${ }^{4,}$

Atendiendo a las diversas técnicas planteadas por Freinet, en las que propugna un método natural donde sea posible la expresión libre y el intercambio y contraste de ideas, el pedagogo propone a Le Corbusier la introducción de talleres dedicados al trabajo manual: "L'emploi scolaire de ces outils nouveaux necessite une

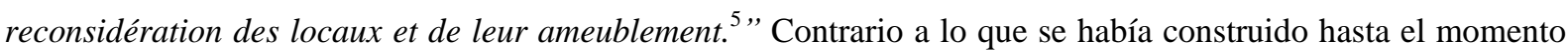
en las escuelas, él propone un concepto de aulas más innovador, rompiendo con la idea de aula tradicional con pupitres individuales. ${ }^{6}$ Según palabras del pedagogo este modo de construir se estaba expandiendo cada vez más, sus técnicas de trabajo habían superado su fase de experimentación y ya estaban puestas en acción. Freinet, en la carta insiste en la construcción de una escuela que responda a los usos y actividades que en ella van a desarrollarse. $^{7}$

En paralelo a estas palabras, entendidas como el inicio de una conversación que forma parte de la evolución de la escuela, Freinet le adjunta unos documentos y un libro ( 'L' Ecole Moderne Français" Fig 1) en los que quedan patentes los intereses de su trabajo. Freinet queda íntegramente a su disposición para cualquier información de utilidad sobre sus técnicas.

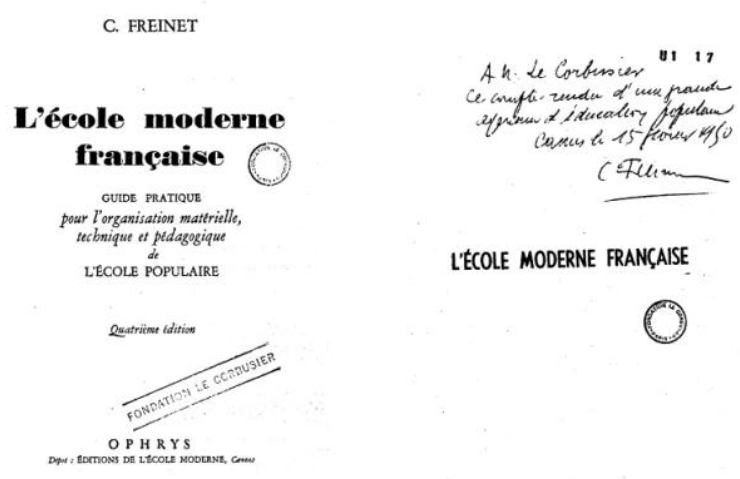

1. Portada de la revista de la documentación sobre l'École Moderne de Céléstin Freinet. OFLC-ADAGP

\footnotetext{
${ }^{3}$ Carta de Céléstin Freinet a Le Corbusier del 14.02.1950 (FLC U1-17 147)

${ }^{4}$ Carta de Céléstin Freinet a Le Corbusier del 14/02/1950 (FLC U1-17 147)

${ }^{5}$ Carta de Céléstin Freinet a Le Corbusier del 14/02/1950 (FLC U1-17 147)

6 “J'ai personnellement mostré la necessité d'une conception nouvelle de L'École-Atelier, comportant une salle commune débouchant sur des ateliers de travail annexes pour les activités essentielles de nos classes. Cette formule se répand de plus en plus comme se répand le principe de la table horizontale qui détrône immanquablement les bancs-pupitres centenaires." Carta de Céléstin Freinet a Le Corbusier del 14/02/1950 (FLC U1-17 147)

7 "Il ne fait pas de doute que les écoles doivent être construites et áménagées en fonction des usagers: élèves et maîtres, et en fonction du travail qu'ils seront amenés à y faire. Vous parlez de réaliser une école-type. Nous serions très heureux que vous puissiez vous interesser à nos techniques de travail qui ont aujourd hui dépassé le stade de l'experimentation pour s'inégrer à la vie de plusieurs dizaines de milliers d'écoles". Carta de Céléstin Freinet a Le Corbusier del 14/02/1950 (FLC U1-17 147)
} 
Le Corbusier responde a su carta el 24 de marzo de 1950 durante su estancia en Sudamérica, aproximadamente un mes más tarde. Explica a Freinet que el Ministerio de Reconstrución y de Urbanismo le está reclamando "les plans relatifs aux classes d'écoles modernes. Le Ministère ajoute, toujours que sa Commission des prototypes va se réunir, etc... ${ }^{\prime 8}$ Sin embargo Le Corbusier afirma que no le importaría ejecutar una clase tipo, como describía anteriormente Freinet, pero es un trabajo extremadamente lento en lo que concierne a la normalización e industrialización. No quiere someterse a la voluntad de los funcionarios del ministerio que después de unos meses le harán saber que no les interesa. ${ }^{9}$

Está de acuerdo con las propuestas de Freinet y cree también en una relación mucho más integral entre educación y espacio. Por otra parte, Le Corbusier está dispuesto a seguir en su atelier con sus inquietudes personales los estudios emprendidos por L'ASCORAL (Asamblea de Constructores para una Renovación Arquitectónica); $;^{10}$

Je serai très heureux de tenir compte de vos suggestions. Soyez assez aimable pour m'en faire part. Je citerai les sources, bien entendu. J'ai lu avec plus grand intérêt vos documents imprimés de l'Ecole Moderne Français. Il est regrettable de voir que la société moderne s'abrutit progresivement à partir de la naissance de ses enfants et cela proportionnellement à l'âge de ses ressortissants. "Il

Le Corbusier

\section{La evolución de la escuela}

Durante el proceso de gestación del proyecto se pueden apreciar variaciones entre los primeros croquis de la escuela en 1944 y los últimos dibujos en 1953. En la Ville Radieuse Le Corbusier ya propone, en la planta penúltima de los bloques, zonas de "culture physique et jeux", "centre familial et santé", y una cubierta con solarium, zona de "enfants", pistas, etc. También en el Immeuble del Bastion Kellerman (1937). Era algo que Le Corbusier consideraba como inherente a un inmueble colectivo, donde se debían dar todas las necesidades. La cubierta de la Cité Radieuse también estaba pensada como un espacio común y a lo largo del proceso de gestación algunos elementos serán permanentes (tas de sable, enfants: hélio et hydrothérapie, plage de sable, piste d'entrainement, vide du gymnase, execrases de plein air, piste de 100m..).

En ese período de idas y vueltas, el programa docente proyectado en la planta 17 de la Cité Radiuese se irá modificando atendiendo a diversas particularidades. En la propuesta de marzo de 1944 se limita a ocupar 6 crujías de 8,38m, como 6 aulas (fig 2) o espacios únicamente abiertos a la terraza hacia el oeste. Estos espacios son independientes y no existe ninguna intención de conectarlos espacialmente. Dentro de cada uno se definen unas necesidades para su correcto funcionamiento como son las zonas de servicios, o la zona de reposo. Se propone una rampa para subir a la cubierta que arranca desde un espacio interior de la escuela situado en el extremo sur.

\footnotetext{
${ }^{8}$ Carta de Le Corbusier a Céléstin Freinet. 24/03/1950 (FLC U1-17 148)

${ }^{9}$ Carta de Le Corbusier a Céléstin Freinet. 24/03/1950 (FLC U1-17 148)

10 "Par ailleurs, je sus prêt à poursuivre, dans mon propre atelier, pour ma délectation personnelle, les études entreprises par L'ASCORAL dans la section "SAVOIR HABITER” à l'école primaire. Carta de Le Corbusier a Céléstin Freinet. 24/03/1950 (FLC U1-17 148)

${ }^{11}$ Carta de Le Corbusier a Céléstin Freinet. 24/03/1950 (FLC U1-17 148)
} 


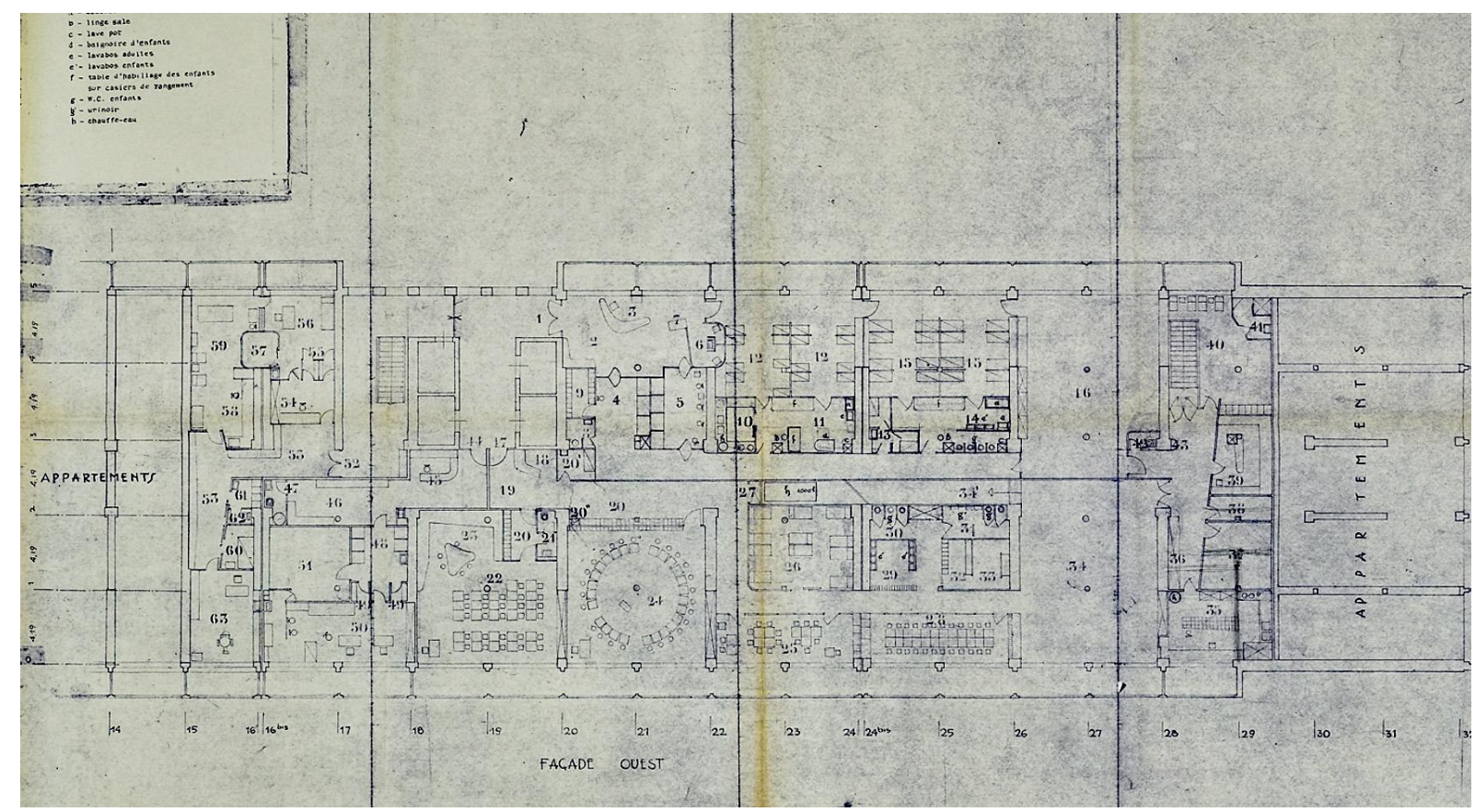

2. Niveau 17. Le Corbusier, Bodiansky. 27/03/1944 (FLC 25360B) OFLC-ADAGP

Dos años más tarde, en la propuesta del 10 de mayo de 1946 (fig 3, 4 y 5), se invierte la posición de "le jardin d'enfants y le service médical" y aparece el gimnasio y los vestuarios en la misma planta. La comunicación vertical es común para estos tres usos, por lo que la escuela pierde esa relación directa que se planteaba en la propuesta anterior a través de la rampa. Ubicada en el lado este, en "le jardin" desaparece esa condición de "aulas" tan definida y quedan espacios más relacionados y abiertos entre sí. En esta propuesta "le jardin d'enfants" se define por los usos y por las actividades que se prevén ("foyer, ping-pong, atelier, musée, bibliothèque.."), como superación de la idea tradicional de aula.

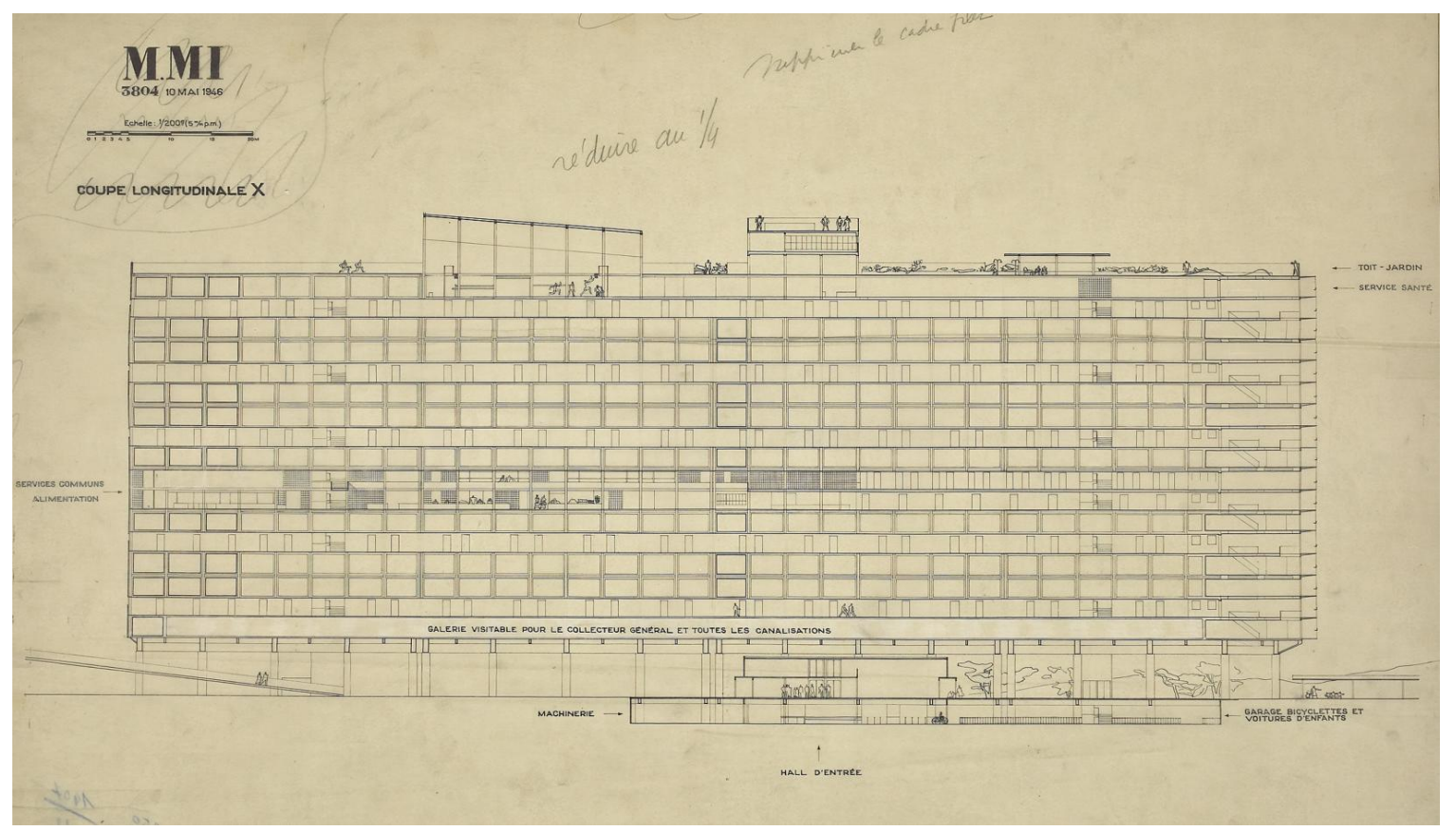

3. Coupé longitudinal. 10/05/1946 (FLC 26314A) @FLC-ADAGP 

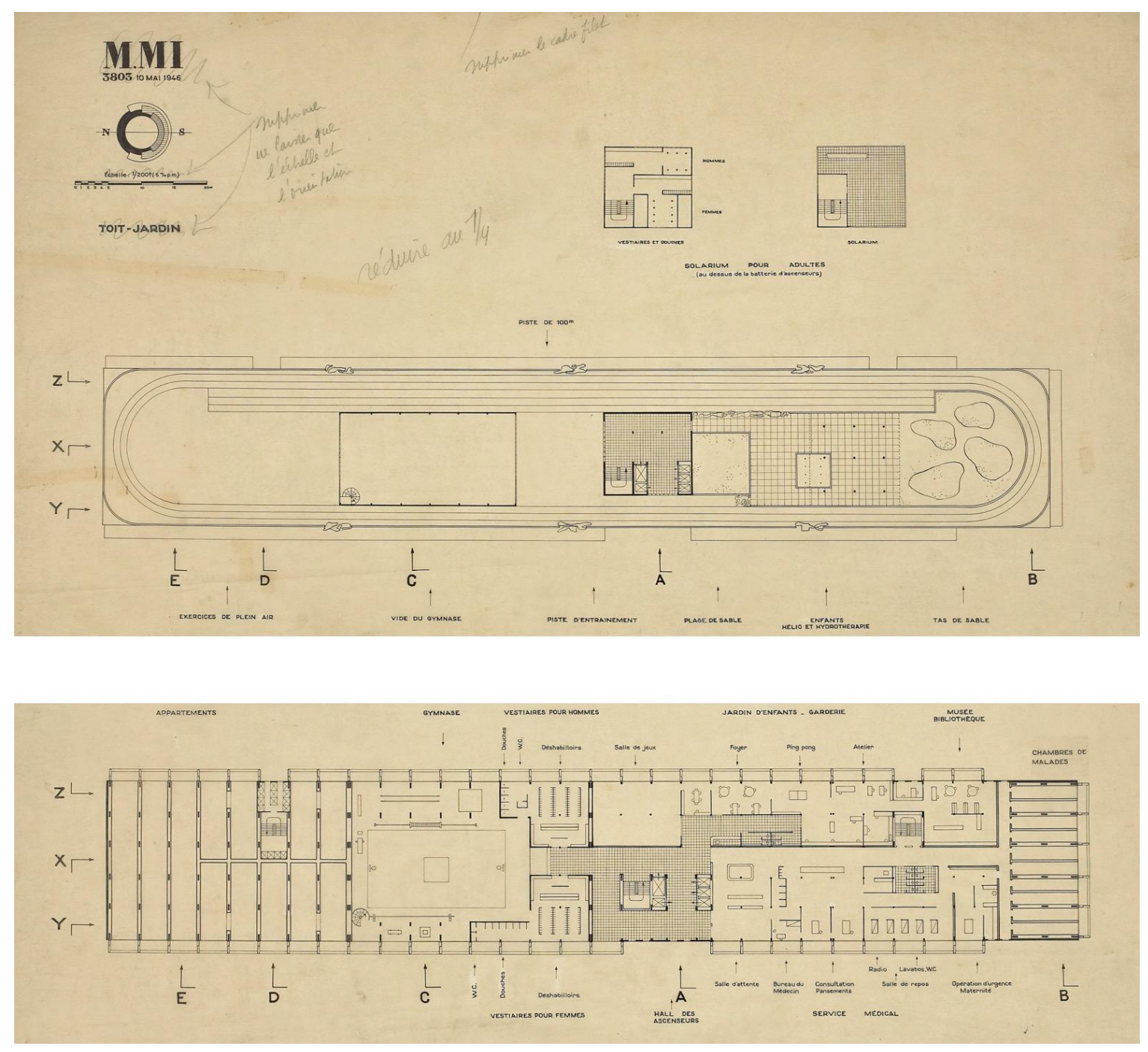

4. Toit-jardin. 10/05/1946 (FLC 26313A) OFLC-ADAGP

5. Services communs sport et santé. 10/05/1946 (FLC 26312A) @FLC-ADAGP

Esta intencionada decisión de clasificar los espacios en función de la actividad prevista únicamente quedará reflejada en esta y en la propuesta de 1947 (fig 8 y 9). Existe otra variación del mismo año (1946), un poco más tardía (fig 6 y 7) donde la escuela recupera esa posición en planta volcada hacia el oeste, mirando hacia el mar. En este caso, la escuela amplía su superficie, el área común se configura como un espacio más generoso desde el cual se intuye la previsión de una escalera de doble tramo para subir a la terraza directamente desde la escuela. Los lugares de aprendizaje quedan comprendidos en un gran espacio y la salle de jeux duplica la superficie que se planteaba en la propuesta anterior. Se podría intuir en la manera en la que se propone el aprendizaje alguna influencia de los principios de la escuela moderna descrita por Freinet; el espacio está pensado para el niño, que es el principal protagonista. 

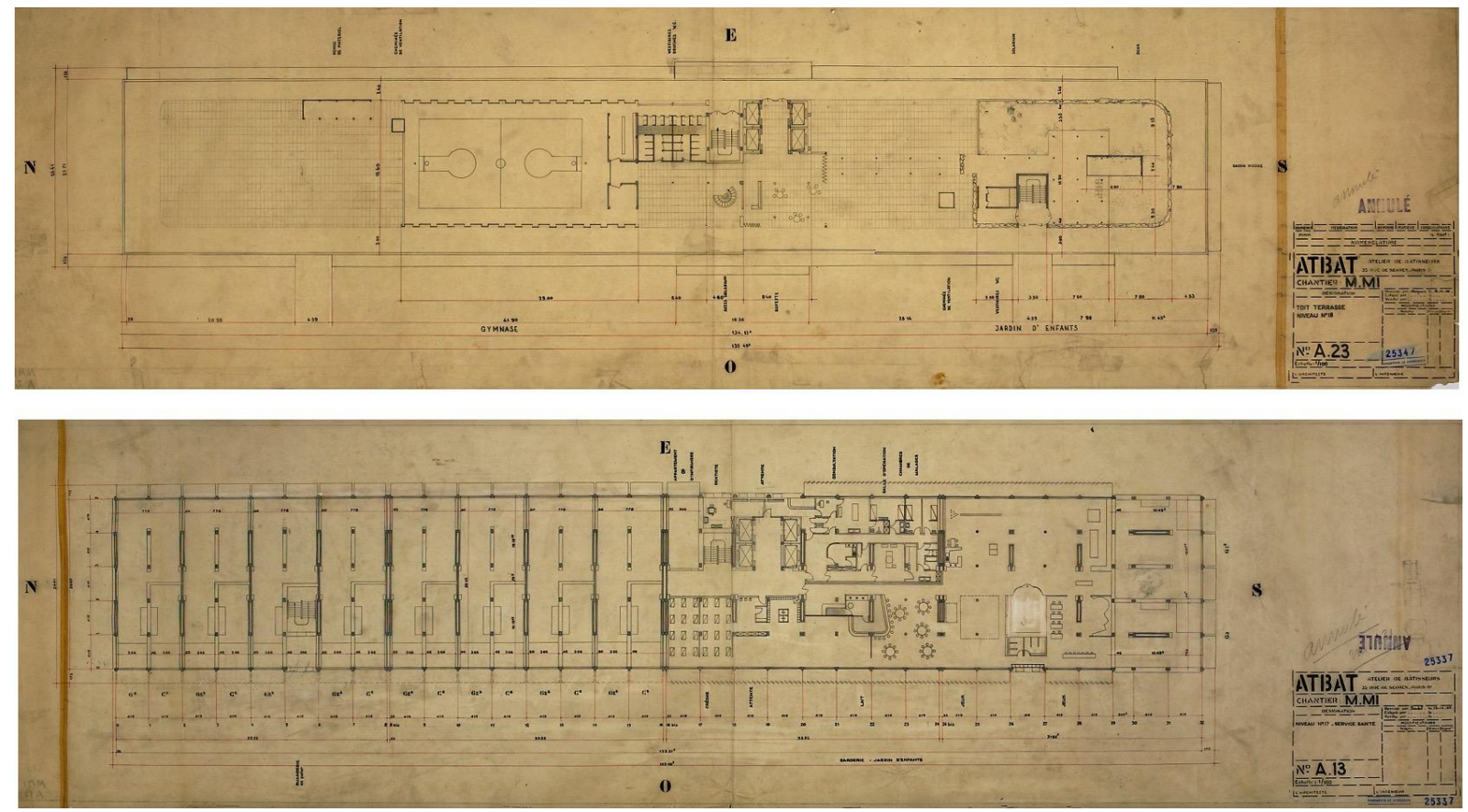

6. Toit-terrasse niveau $n^{\circ} 18.13 / 12 / 1946$ (FLC 25347) CFLC-ADAGP

\section{Niveau $n^{\circ} 17$ service santé. Badel. 12/12/1946 (FLC 25337) @FLC-ADAGP}

Las variaciones realizadas en la propuesta de febrero de 1947 ( fig 8 y 9) mejoran la escuela desde el punto de vista espacial y funcional. Se recupera la rampa, que en este caso de podría entender como un elemento de juego que forma parte del espacio docente. El hecho de establecer una conexión entre las dos plantas significa que la escuela se apropia de la cubierta, que en la propuesta final acabará siendo la parte del programa más abierta. El primer tramo invade la sala de juegos dando pié a que la superficie inclinada sea susceptible de ser utilizada desde la escuela. Se intuye que la rampa está abierta a los espacios docentes y forma parte de una promenade architectural que explica el funcionamiento de la escuela. Es en definitiva una propuesta en la que se definen los espacios en función de su uso, acondicionándolos a través de elementos ligeros, con soportes capaces de facilitar la tarea a desarrollar y con piezas de mobiliario adaptados a la escala del niño. Esos espacios bañados de luz, comunicados entre sí, presentan esa condición de generar una comunidad en la que todos aprenden de todos.

En la propuesta de 1947 Le Corbusier apuesta por no jerarquizar los espacios, construyendo un lugar común en el que no son tan importantes los elementos fijos o la división en estancias sino los usos que se van a desarrollar y que por sí mismos ordenarán el espacio. Esos usos aparecen nombrados en la planta, que solo se entiende cuando se dibujan también los muebles (testigos del uso del espacio) que además se colocan en los lugares intermedios (en los intersticios), cosiendo unos espacios con otros y construyendo un gran salón de aprendizaje. Es además una propuesta muy generosa en superficie y que evita segregar a los niños por su edad en aulas con pupitres. Es una idea por tanto muy cercana a los planteamientos de Freinet, y se puede suponer que el Ministerio fue el causante de los cambios a partir de este momento, pues desde esta propuesta las demás versiones irán alejándose de esos planteamientos. 

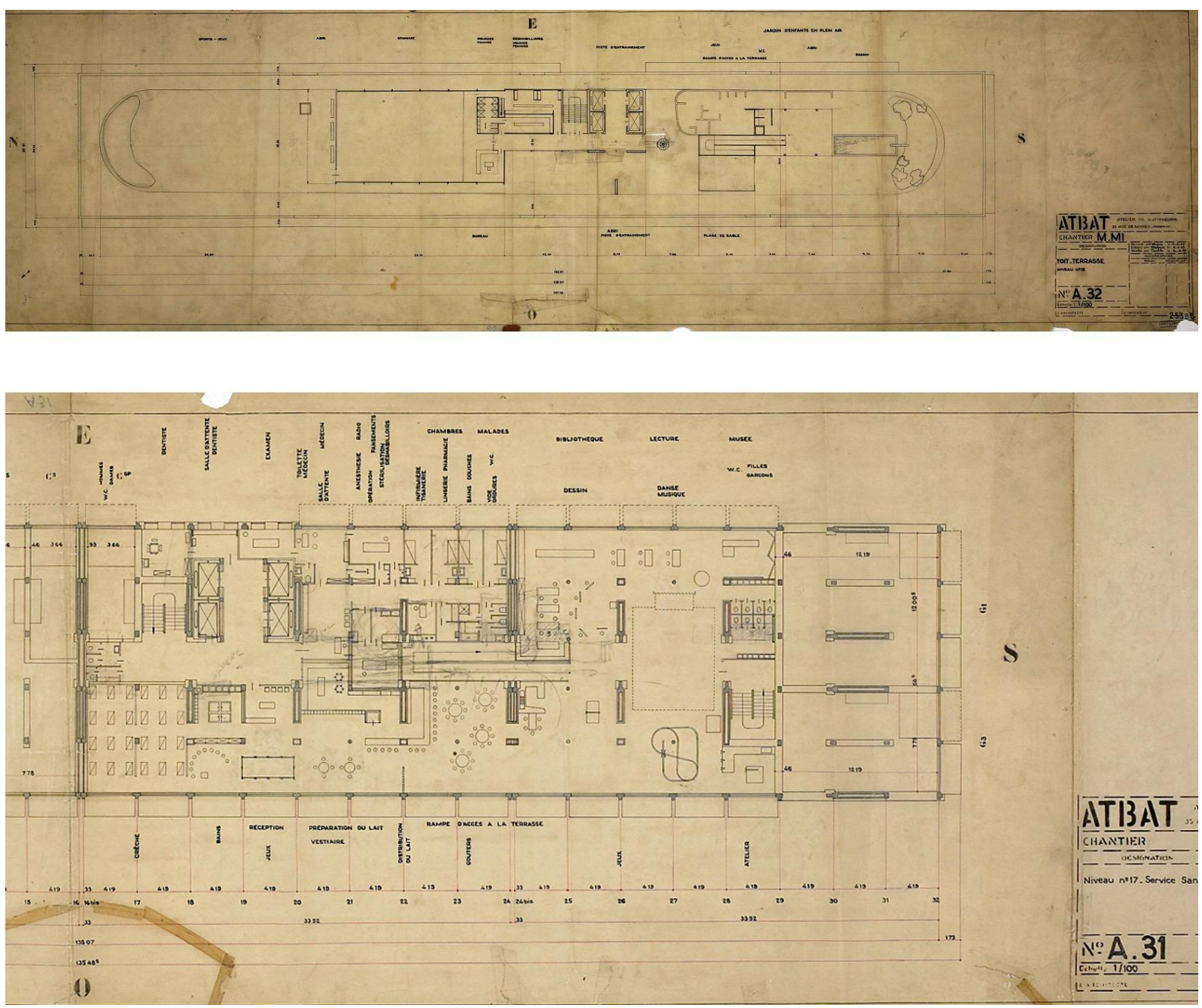

8. Toit-terrasse niveau $n^{\circ} 18.11 / 02 / 1947$ (FLC 25356A) OFLC-ADAGP

9. Niveau $n^{\circ} 17$ Service Santé. Badel. 05/02/1947 (FLC 25355) CFLC-ADAGP

Hasta este momento, la escuela se entendía como parte del programa de servicios comunes que Le Corbusier proponía dentro de l'Unité d'habitation. En las diversas propuestas (hasta 1949) descritas hasta ahora, el propio Le Corbusier había proyectado la escuela atendiendo a sus propios criterios e intenciones sin atender al reglamento vigente.

En 1951, André Wogenscky escribe una carta a Le Corbusier, "Le ministère me demande s'il est possible de prévoir une école sur le terrain de l'Unité. "12 Un año antes de la finalización de las obras, el tipo de escuela no está definido, y meses después de la inauguración del edificio, gracias a la complicidad feliz y determinada entre Le Corbusier y su futura directora, Lilette Ripert (Mme Ougier), el centro encontraría su lugar.

Los dibujos posteriores a 1949, que son los que finalmente se ejecutan, recuperan un concepto de "aulas" más convencional, en el que se clasifican los espacios según las edades y se rechaza la idea de asumir la escuela como un gran espacio acondicionado para unas actividades concretas. Tras el encargo de 1951 se podría sospechar que en la reconversión de la escuela en "aulas", similar a la propuesta de 1944 y alejada de la propuesta más ambiciosa de 1947, Le Corbusier está condicionado por las normativas vigentes en ese momento.

\footnotetext{
${ }^{12}$ Sbriglio, Jacques. Le Corbusier, L'Unité d'habitation de Marseille. Carta de André Wogenscky a Le Corbusier, 12/09/1951. (FLC R3-8-3)
} 
A partir de 1950, año de la correspondencia entre Le Corbusier y Céléstin Freinet, se comienzan a realizar los planos finales para la ejecución de la escuela. Tal como refleja Le Corbusier en la carta para Freinet del 24 de marzo de 1950, se muestra desilusionado por los plazos y la mala organización que el ministerio presenta ante cualquier propuesta...

"Or, je veux bien exécuter avec le plus entier dévouement une classe type à mettre dans n'importe quel village, travail extrêmement lent de normalisation et d'industrialisation,mais je n'ai aucun désir de soumettre à des fonctionnaires du Ministère qui ne feront savoir quelques mois plus tard que cela ne les intéresse pas de tout et, s'ils daignent me répondre... ",13

Para explicar la propuesta que finalmente se ejecuta se atenderá en orden cronológico a la correspondencia mantenida entre Lilette Ripert y Le Corbusier a lo largo de la vida útil de la escuela para recorrer desde los rincones más recónditos hasta la pista al aire libre pasando por la rampa y subiendo a la crèche. Lilette Ripert dará pistas de cómo se usaron aquellos lugares pensados y proyectados para el niño. La correspondencia, los dibujos, los planos y las fotografías serán las claves para comprender e imaginar el edificio construido desde su uso, y que Lilette Ripert y los niños fueron capaz de exprimir hasta sus últimos días.

\section{Hacia una pedagogía más humana}

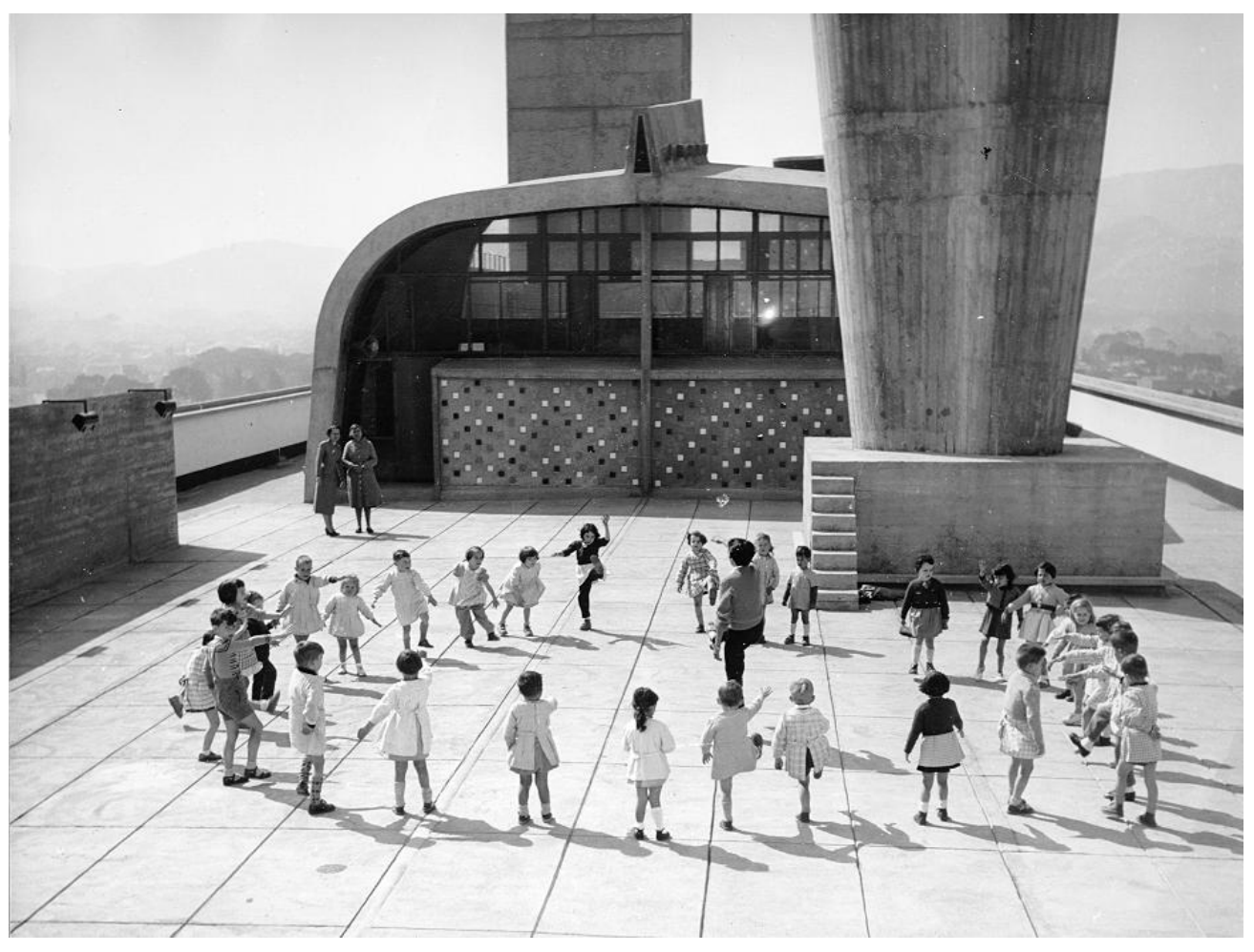

10. Toit-terrasse. Les Maternelles Michelet-Marseille. (FLC L1-11 1) @FLC-ADAGP

\footnotetext{
${ }^{13}$ Carta de Le Corbusier a Céléstin Freinet. 24/03/1950 (FLC U1-17 148)
} 
"Le jour de l'ouverture de la Maternelle, les mamans, leurs gosses à la main, sont montées sur le toit. Elles ont été éblouies par la splendeur du spectacle: ciel, monts, mer, îles...et architecture.,"14

Lilette Ripert, ferviente admiradora de Le Corbusier, colaboradora de Freinet, y apasionada por su trabajo, entendió la escuela utilizándola ${ }^{15}$, siendo capaz de aplicar el método educativo utilizando los espacios proyectados por Le Corbusier (fig 10).

El programa educativo que implanta Lilette Ripert en la escuela abarca numerosas actividades que incitan a un esfuerzo por parte del niño. Freinet defendía que el trabajo escolar debía tener un sentido, una utilidad y una función. Dentro del marco de actividades desarrolladas reinaba la educación artística sobre el resto, pero además, el programa contemplaba juegos sensoriales, la iniciación a la escritura, al cálculo, a la lectura, al canto y a la educación física. ${ }^{16}$ Para aplicar el principio de cooperación defendido por Céléstin Freinet se exigía la creación de un ambiente en el aula en el que existieran elementos mediadores en la relación maestro-alumno. Era necesaria la cooperación entre alumnos, alumnos-maestros y entre maestros, con la finalidad de compartir experiencias y dialogar, poniendo en común los problemas y las posibles soluciones. La organización del aula debía contemplar la participación de los alumnos en la construcción de sus conocimientos, potenciando el trabajo de clase sobre la base de la libre expresión de los niños en un marco de cooperación. ${ }^{17}$ El término de escuela no se limita únicamente al espacio clasificado como tal, sino a todo espacio o elemento capaz de generar una situación en la que niño pueda imaginar, jugar y por lo tanto, aprender. "L'école" se desarrolla en dos niveles superpuestos, físicamente relacionados. Ambos lugares, a pesar de tener unas condiciones físicas muy alejadas, son lugares flexibles que permiten al niño sentirse libre, poder recorrerlo con libertad, experimentar y conocer.

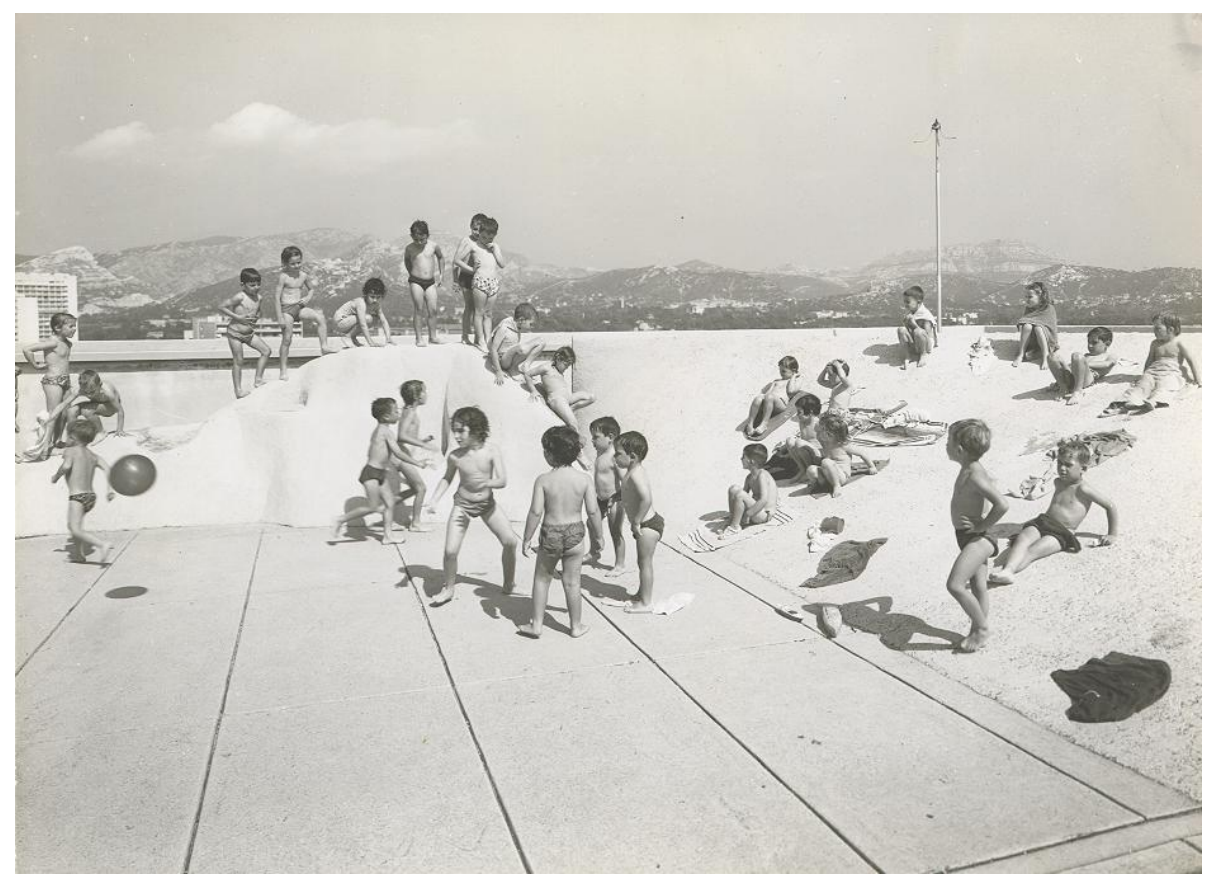

11. Toit-terrasse Les Maternelle Michelet-Marseille. (FLC L1-11-42) @FLC-ADAGP

\footnotetext{
${ }^{14}$ Le Corbusier, Les Maternelles vous parlent. p. 57.

15 "An architecture called total arquitecture as a further step to the expression of full life; life which is substituting the work 'to possess' by the word 'to use' J. Bakema (FLC D3-19 81-83)

${ }^{16}$ Le Corbusier, Op. cit., p.59.

${ }^{17}$ Freinet, Céléstin. L'éducation du travail, París, Editions Ophrys, 1949.
} 
Según el análisis de Le Corbusier, la función principal de la cubierta era reemplazar la vegetación parcialmente demolida para la construcción del edificio. Mientras que las bóvedas del techo de la Maisons Raoul (1951-55) en Neuilly-sur-Seine y en la cubierta de la Petite Maison de fin de semana en La Celle-Saint-Cloud brotaba hierva en abundancia, en la cubierta de L'Unité d'habitation de Marseille la vegetación no adquiere esa importancia. La ausencia de la naturaleza se manifestó con claridad, y en su lugar nos encontramos con una serie de sustitutos con formas orgánicas. ${ }^{18}$ Los niños viven la naturaleza pero con formas abstractas que pueden asemejar las de la naturaleza de su alrededor que ven desde lo alto del edifico (fig 11). La pequeña piscina para los niños mantiene una relación con el océano ( $f$ ig 12), mientras que los montículos de hormigón proporcionan una analogía metonímica de la cordillera trasera."The Sardinian mason Salvatore Bertocchi was given a free hand to design these two fantasies as a playground for children in the infants's school." 19 Tim Benton señala que el análisis de Stanislaus Von $\operatorname{Moos}^{20}$ termina con una especulación sobre la manera en la que el edificio, y concretamente la cubierta, se podría considerar "orgánica”, centrándose en particular en las asociaciones espirituales y metafóricas de la naturaleza, derivadas del crítico inglés, John Ruskin. "Von Moos remarks that the high balaustrada of the roof terrace concludes most of the surrounding landscape, allowing a view only of the hills framing the caray silhouette of the Calanques behind. "21 La superficie vertical de 1,60 del antepecho construye, desde la mirada de un niño, el marco de un lienzo que encierra el paisaje circundante: la silueta de las montañas, el sol y el cielo.

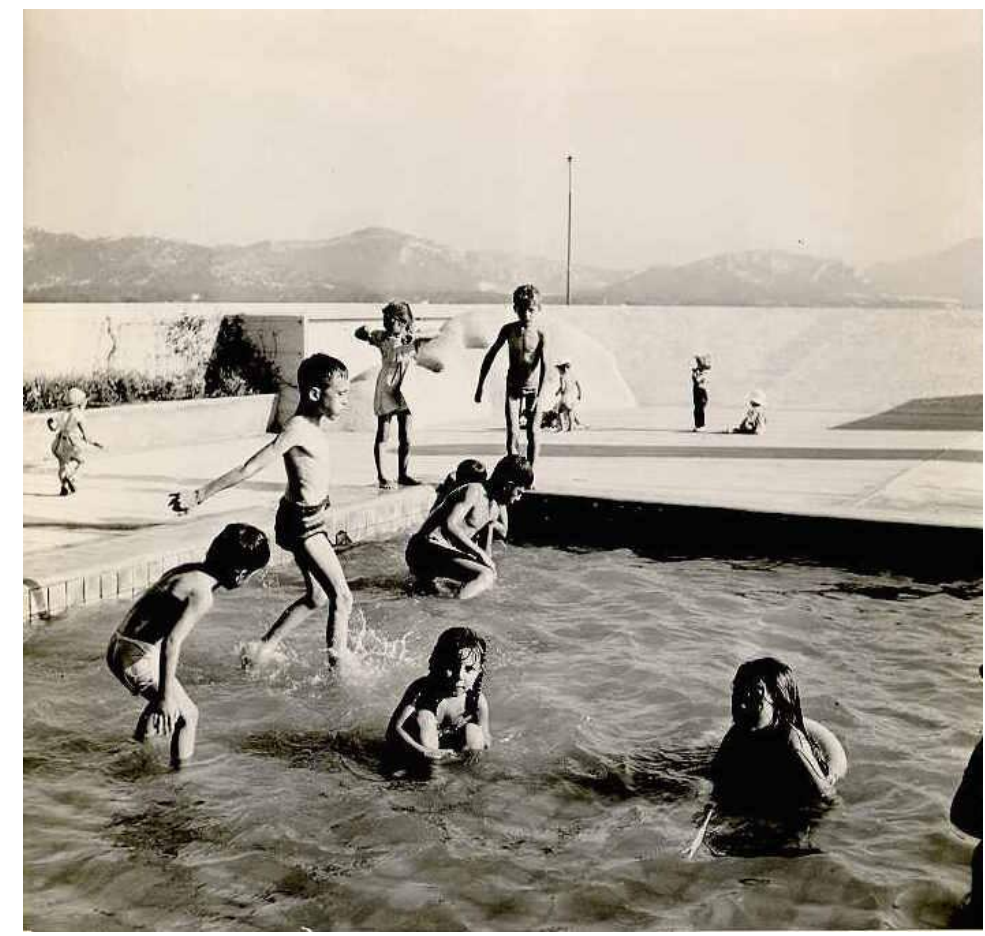

12. Toit-terrasse Les Maternelle Michelet-Marseille. (FLC L1-11 12) @FLC-ADAGP

\footnotetext{
${ }^{18}$ Benton, Tim. Marseille: Unité d'habitation or "The company of clouds, he sky, os the stars." In: Cohen, Jean-Louis ed. Le Corbusier: an Atlas of Modern Landscapes, 2013, New York: Museum of Modern Art, pp. 201-211.

${ }^{19}$ Ibid.

${ }^{20}$ Stanislaus, Von Moos. Machine and nature: Notes a propos de l'Unité d'habitation de Marseille," in Claude Prelorenzo, ed., Le Corbusier: La Nature (1991: Paris Éditions de La Villette, 2004), p.48.

${ }^{21}$ Ibid.
} 
La cubierta elevada 56m sobre rasante, orientada en el sentido longitudinal norte-sur al aire libre con vistas lejanas hacia el entorno, constituye un escenario suspendido para el niño (fig 13). Una sensación de estar permanentemente volando (fig 11). Von Moos apunta que el rechazo de mirar hacia algunas zonas del entorno tiene ese efecto de dirigir el mirada hacia adentro, sobre el grupo de formas y funciones montadas sobre la cubierta: dos grandes chimeneas de ventilación, una torre de ascensores y de reserva de agua, una sala de educación física, una guardería, un teatro al aire libre, una pista, una piscina, un espacio cubierto, unas colinas artificiales, unos planos inclinados..."The strong vertical elements-the elevator tower and the ventilation stackplay off against the more intimate lower structures (fig 14)." 22 Frente a lo construido, el sol, el mar, las montañas, el viento y el cielo son los fenómenos naturales que estaban allí antes y que todavía permanecen.

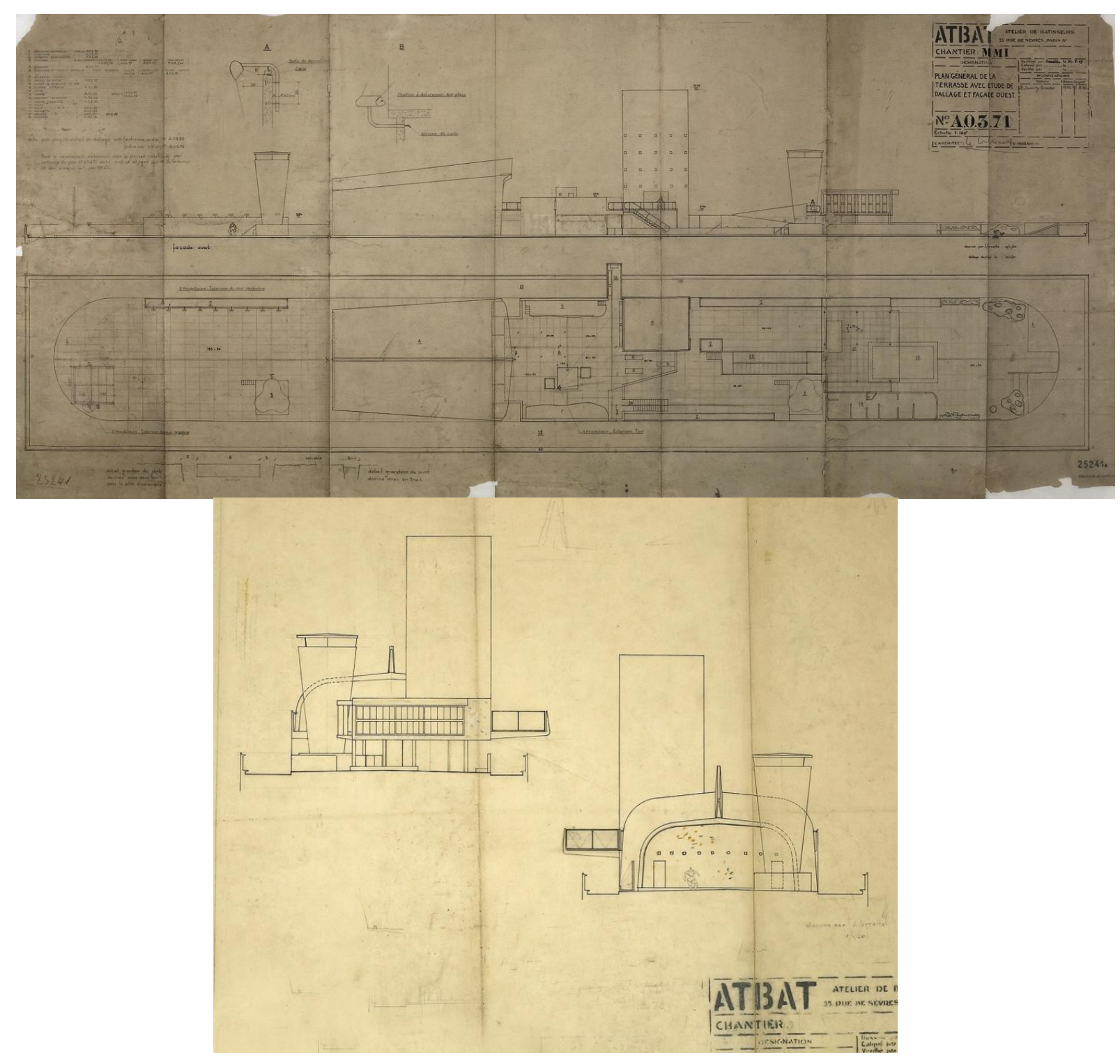

13. Toit-terrasse Les Maternelle Michelet-Marseille. (FLC 25241A) OFLC-ADAGP

14. Facade North-South. Le Corbusier. 18.1949. (FLC 25243) @FLC-ADAGP

\footnotetext{
${ }^{22}$ Benton, Op.cit., p. 201-211.
} 
Tal como revela la correspondencia, Le Corbusier, desde los inicios, toma parte junto con Lilette Ripert en el desarrollo de las actividades que tuvieron lugar en la escuela. Será el propio arquitecto quien dé órdenes y consejos sobre la manera en que deben realizarse ciertas tareas. Uno de los primeros proyectos desarrollados fue pintar el antepecho perimetral de hormigón (fig 15). ${ }^{23}$ Le Corbusier, le aconseja utilizar los muros ocultos por los planos inclinados para realizar las primeras pruebas, "et si cela va bien, essayer sur les murs à gauche et a droite des Dromadaires "24 y que haría falta encontrar un truco con el andamio para que los niños puedan pintar más alto y que el dibujo ocupe toda la superficie llegando hasta lo más alto. "Je vous donne un croquis.... Les gosses sont généralement graphiques, ils dessinent avec les pinceaux. $N$ 'hesitez pas à les pousser à faire des surfaces, de grands emplâtres. " 25 Entre varios de los propósitos de Le Corbusier en relación a las actividades realizadas por los niños en la escuela, "Je voudrais que, pour le mois de juillet, quelques peintures soient faites déjà (pour le Congrès du 25ème anniversaire des CIAM). "26

Lilette Ripert seguirá todas las indicaciones y así comenzaron a realizar los primeros ensayos sobre el lavabo y sobre la pista, detrás del plano inclinado. Los niños estaban emocionados de pintar sobre el muro y de trabajar sobre la cubierta. ${ }^{27}$ Es una muestra de cómo el arquitecto tiene también la responsabilidad de educar en el proceso de la arquitectura misma, enseñando a usar, a comprender el espacio y transmitiendo la manera en la que ha creído que va a utilizarse; bajo la idea de que un edificio no se termina cuando se entrega al habitante.

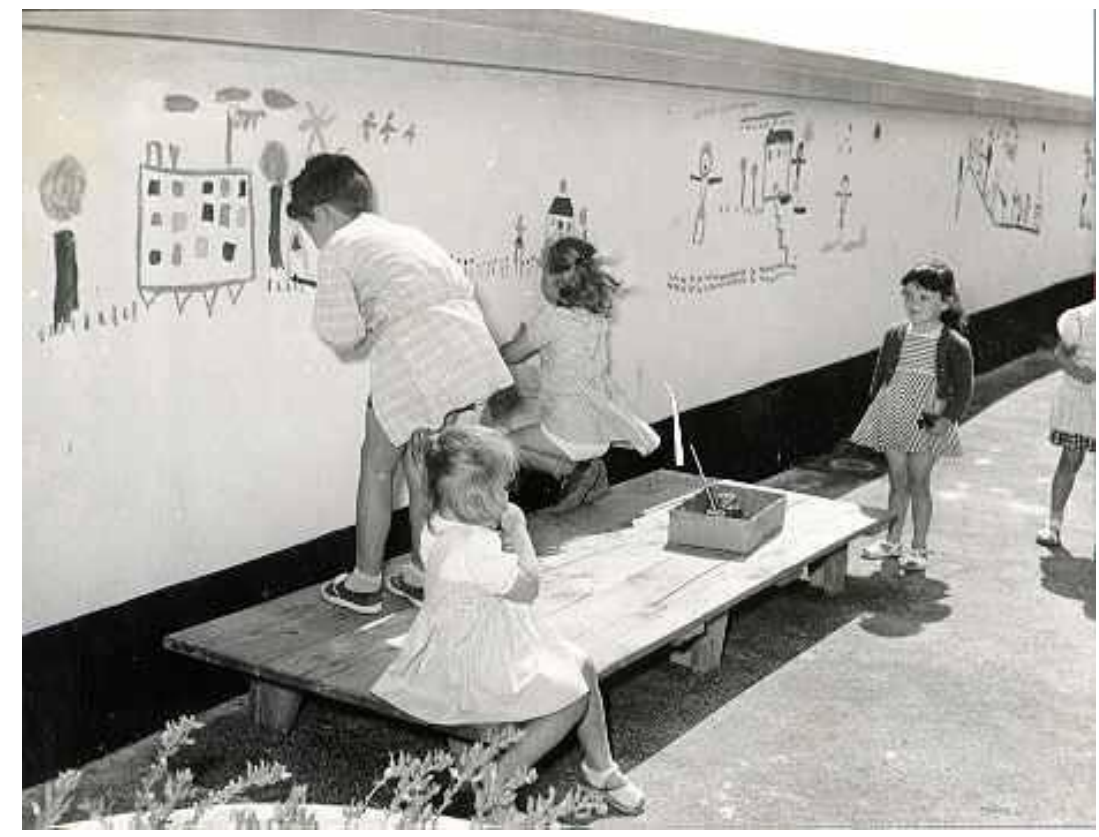

15. Decoración del antepecho que construye el límite de la cubierta. Sciarli. (FLC L1-11 77) OFLC-ADAGP

\footnotetext{
23 "Concernant la frise à faire exécuter par les gamins, il faudrait procéder ainsi: on vous fera un échafaudage de contreplaqué de 2 m26 de long qui permettra aux enfants de faire un motif de même étendue" y prosigue, "Les motifs de $2 \mathrm{~m} .26$ de long environ, seraient espacés les uns des autres par un intervalle de $1 \mathrm{~m}$, de $50 \mathrm{~cm}$, de $1 \mathrm{~m} 50$, selon les cas". Carta de Le Corbusier a Lilette Ougier (Ripert, N.D.E) del 21/04/1953 (FLC O2-4-4)

${ }^{24}$ Carta de Le Corbusier a Lilette Ougier (Ripert, N.D.E) del 21/04/1953 (FLC O2-4-4)

${ }^{25}$ Carta de Le Corbusier a Lilette Ougier (Ripert, N.D.E) del 21/04/1953 (FLC O2-4-4)

${ }^{26}$ Carta de Le Corbusier a Lilette Ougier (Ripert, N.D.E) del 21/04/1953 (FLC O2-4-4)

${ }^{27}$ Carta de Lilette Ougier (Ripert, N.D.E) a Le Corbusier del 8/05/1953 (FLC
} 
En el nivel 17, junto al núcleo de comunicación, se accede a la escuela. Un tabique curvo que encierra una sala de espera, el gabinete médico del centro escolar y el despacho de la directora, conduce al visitante hacia el interior de l'école. Se circula por un corredor delimitado por el muro que construye el primer tramo de la rampa y una pared con los casilleros, desde donde se accede al aula de los niños entre 4 y 6 años en el lado este. El final de perspectiva del recorrido es la sala de juegos, el espacio común más amplio en esta planta. La salle d'accueil et des jeux es pasante y tiene una fila de pilares circulares en el centro (en sentido transversal), pero que no divide el espacio, ya que las crujías de 4,19m son suficientemente anchas para desarrollar las actividades de teatro, danza, cine... Es además el lugar donde asciende la rampa para subir a la cubierta, y está directamente vinculado al rincón de cocina y una sala común a la escala de los niños.

El techo del perímetro de la planta está ligeramente elevado (sección fig.16) con respecto a los espacios interiores, consiguiendo más altura en las fachadas. Este perímetro más alto coincide con el ámbito del aula que queda abierta al espacio contiguo, y por tanto construye el recorrido espacial que une todos los lugares de la escuela.

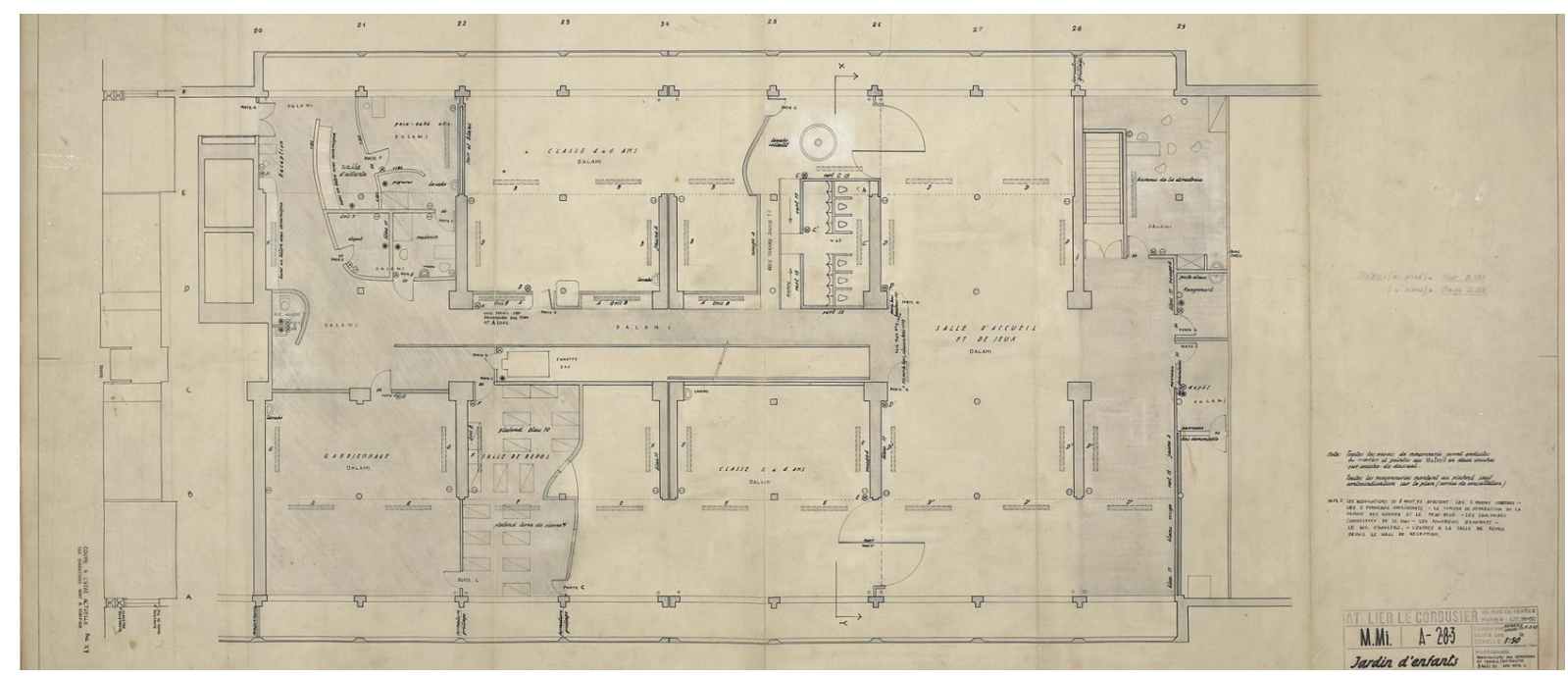

16. Jardin d'enfants niveau 17. Le Corbusier, Xénakis, Sachi. 02/02/1953 (FLC 25668A) OFLC-ADAGP

Los cerramientos que compartimentan los espacios coinciden con los ejes de estructura de hormigón. Las unidades, de proporciones iguales, prácticamente cuadradas, están abiertas hacia el paisaje en uno de sus lados. Tal y como se muestra en la sección transversal el espacio está sutilmente fragmentado de manera que la zona más alejada del exterior queda más comprimida. La línea de estructura marca el límite entre el exterior y el interior. Este paramento transparente, desde el cual se sale a la terraza que recorre longitudinalmente el edificio, tiene la base construida de 80 centímetros (altura de un niño) como elemento de almacenaje (fig 19). A través de ella los niños miran, igual que lo hacen a través del antepecho de la terraza que está construido como una celosía, parcialmente abierta (fig 17). La sala de gardiennage, junto a la salle de repos, la de los niños entre 2 y 4 años y la de los de 4 a 6 (fig 16) son los espacios principales y como muestran las fotografías, pronto quedaron colonizados por sus usuarios. Entre estos espacios se encuentra la zona de servicios, la salle de jeux y la zona administrativa. Estas zonas secundarias se delimitan por paredes onduladas de albañilería y pintadas con pintura Matroil. El bloque sanitario, según indicaciones en los planos, debía colocarse junto a la sala de recepción para que la persona que supervisaba pudiera controlar a la vez. Disponía de elementos colectivos, como la fuente circular (fig 18), donde los niños se lavaban la manos conjuntamente y que, como si de una escultura se tratase, 
se disponía fuera de los inodoros, junto a la sala de juegos, en el espacio intermedio y con un uso mixto que invitaba a entender la higiene como entretenimiento y aprendizaje.
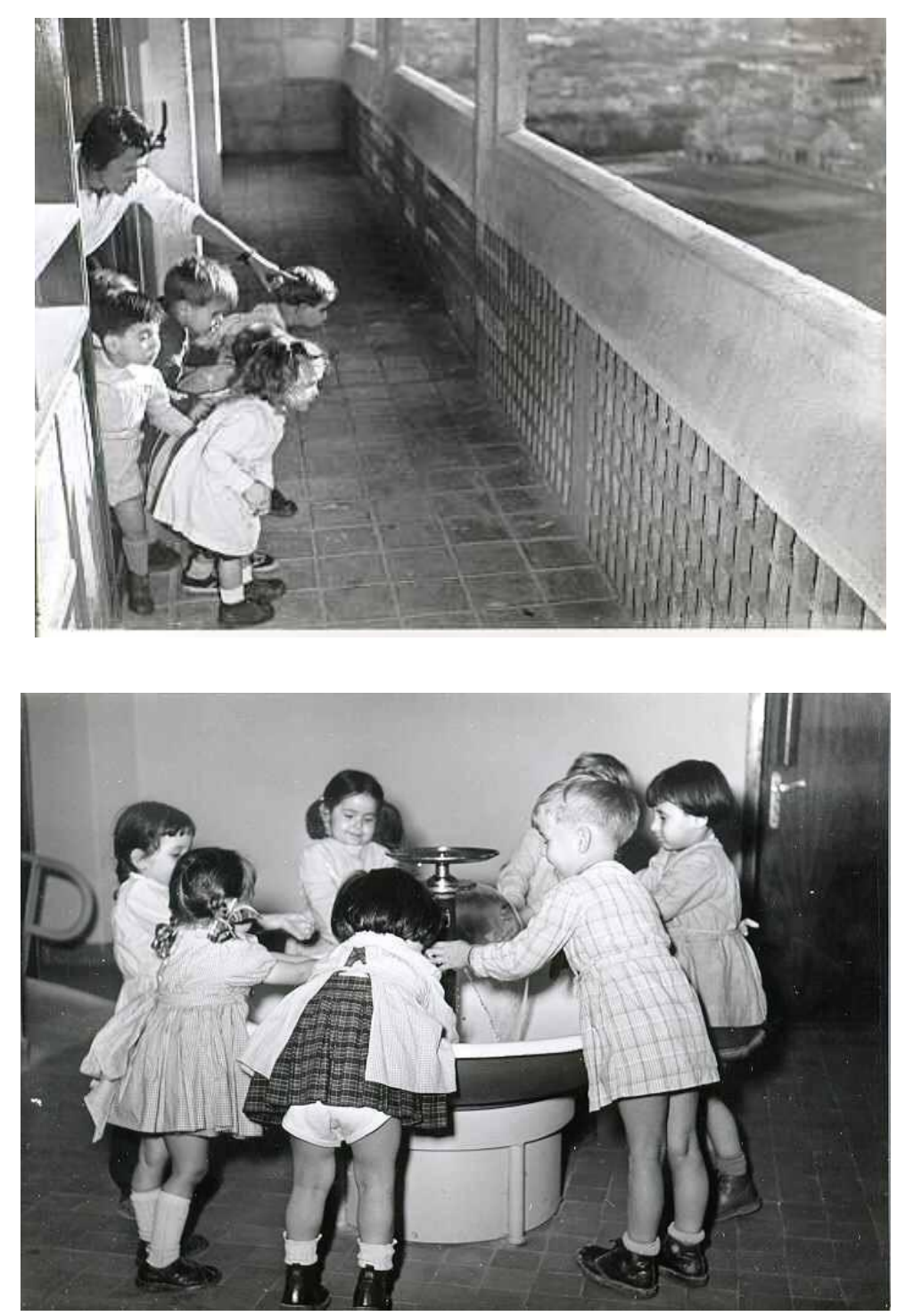

17. Los niños miran desde la terraza. Jardin d'enfants niveau 17. (FLC L1-11 104) OFLC-ADAGP

18. Los niños lavándose las manos. Jardin d'enfants niveau 17. (FLC L1-11 98) OFLC-ADAGP

Utilizando el plan libre, incorpora una serie de espacios que aseguran a la vez la flexibilidad y la intimidad necesarias para el funcionamiento de este tipo de equipamientos. Los puntos de apoyo, los casilleros, los muebles de almacenamiento, los juegos de curvas, la rampa, la policromía aplicada directamente sobre el hormigón en bruto, acompañará a las instalaciones en esta escuela que reflejan una gran atención a la escala del niño. 

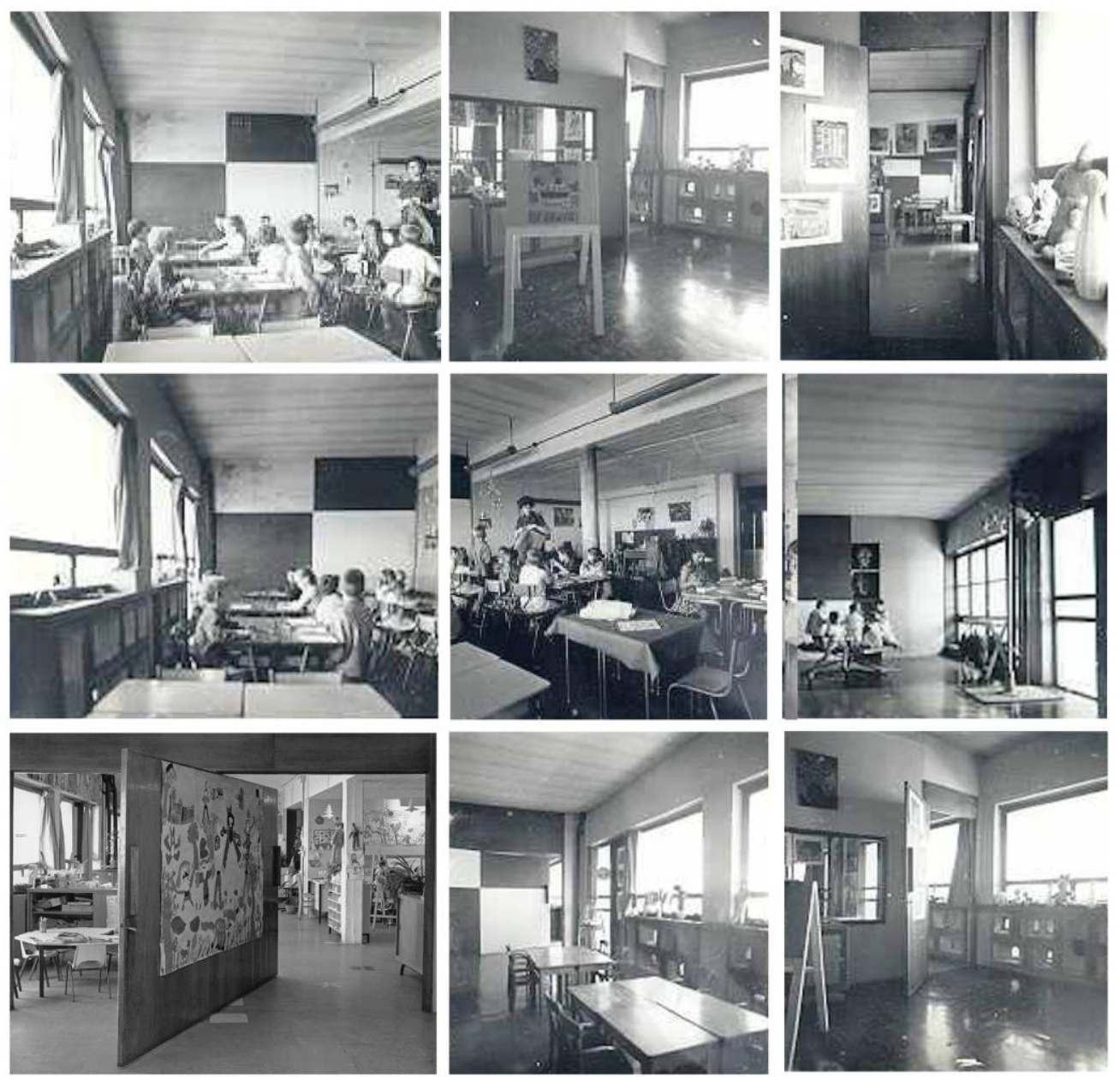

19. El interior. Jardin d'enfants niveau 17. (FLC L1-11-116-117) OFLC-ADAGP

Las superficies planas, onduladas, las pizarras, las puertas pivotantes (fig 19) son elementos que delimitan espacios, que construyen barreras, pero en la mayoría de los casos se aprovechan como superficies susceptibles de utilizarse como tableros sobre los que pintar y dibujar. Lilette Ripert consultaba a Le Corbusier sobre cómo pintar estos tableros. ${ }^{28}$ Son elementos que aúnan varios usos, como los montículos sobre los que los niños escalan, pero que también utilizan como jardineras artificiales que mantenían diariamente (fig 20). ${ }^{29}$ Siempre con esa intención de utilizar todo para varias cosas, de aprovechar cualquier resquicio y rincón para convertirlo en un lugar que los niños pueden usar de otras maneras, que es capaz de activar su creatividad como proponía Freinet, y al fin y al cabo de motivar su aprendizaje.

\footnotetext{
28 “ $1^{\circ}$. Elle vous attendait impatiemment pour vous demander comment peindre les tableaux au mur de la troisième classe mise en service. Je lui ai conseillé de la faire elle-même en s'inspirant des deux autres classes. $2^{o}$. Elle réclame impatiemment les indications de couleurs pour ses meubles d'école. $3^{\circ}$. Elle m'a demandé d'ecrire à Calder pour qu'il offre un "mobile” à l'école. Qu'en pensez-vous?.” Nota a la intención de Le Corbusier de A. Wogenscky el 1/10/1954 (FLC) 29 "Il faudrait faire photographier les enfants au moment où les uns peindront autour de la piste et ou d'autres jardineront dans les caisses à fleurs, plantant quelque chose ou arrosant, et ainsi de suite." Carta de Le Corbusier a Lilette Ougier (Ripert, N.D.E) del 13/05/1953 (FLC E2-17 361)
} 


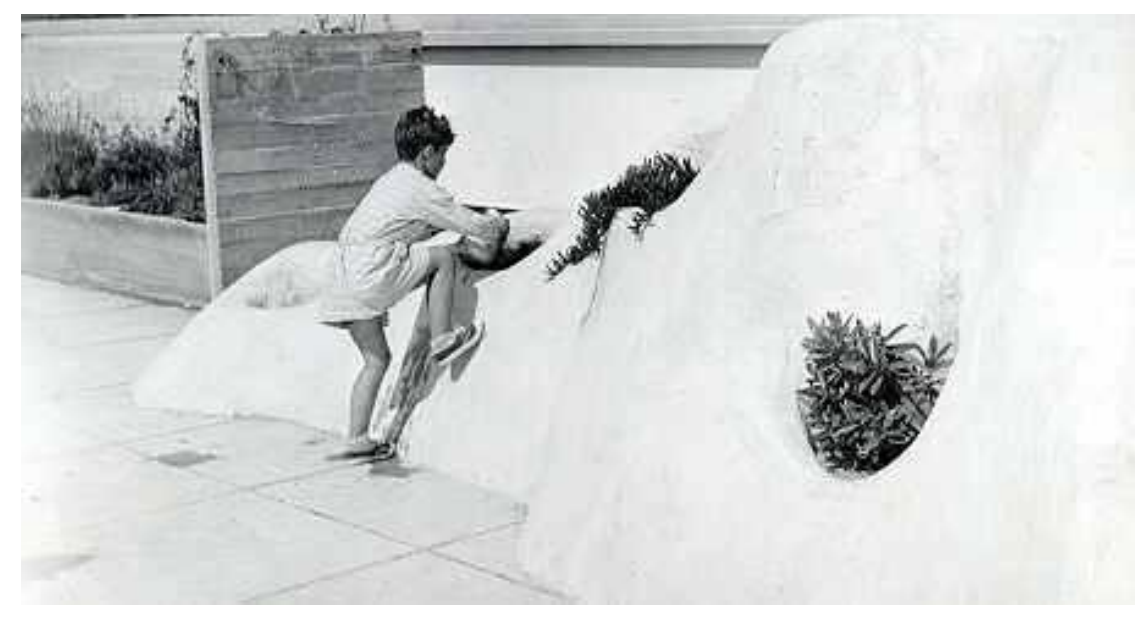

20. Jardinería. Toit-terrasse 17. (FLC L1-11 49) OFLC-ADAGP

Desde la apertura de l'école en 1953 se comienza con la elaboración de fotografías, documentos, dibujos (fig 21), cartas, escritos que hablan de ese proceso tan activo y enriquecedor que la escuela desarrolló durante más de una década. ${ }^{30}$ Lilette Ripert pronto descubrirá la necesidad de construir un documento capaz de contener los trabajos realizados por los niños. Freinet, entre sus propuestas, hablaba de la revista escolar que se origina con las producciones infantiles y se realiza a partir de la propia organización del trabajo. "Quand tout sera un peu rodé j'essayerai de portés enfin le petit cahier d'experiences pédagogiques réalisées dans la joie dans notre école de plein ciel- cahier auquel j'ai beaucoup réflechi depuis un an. "31

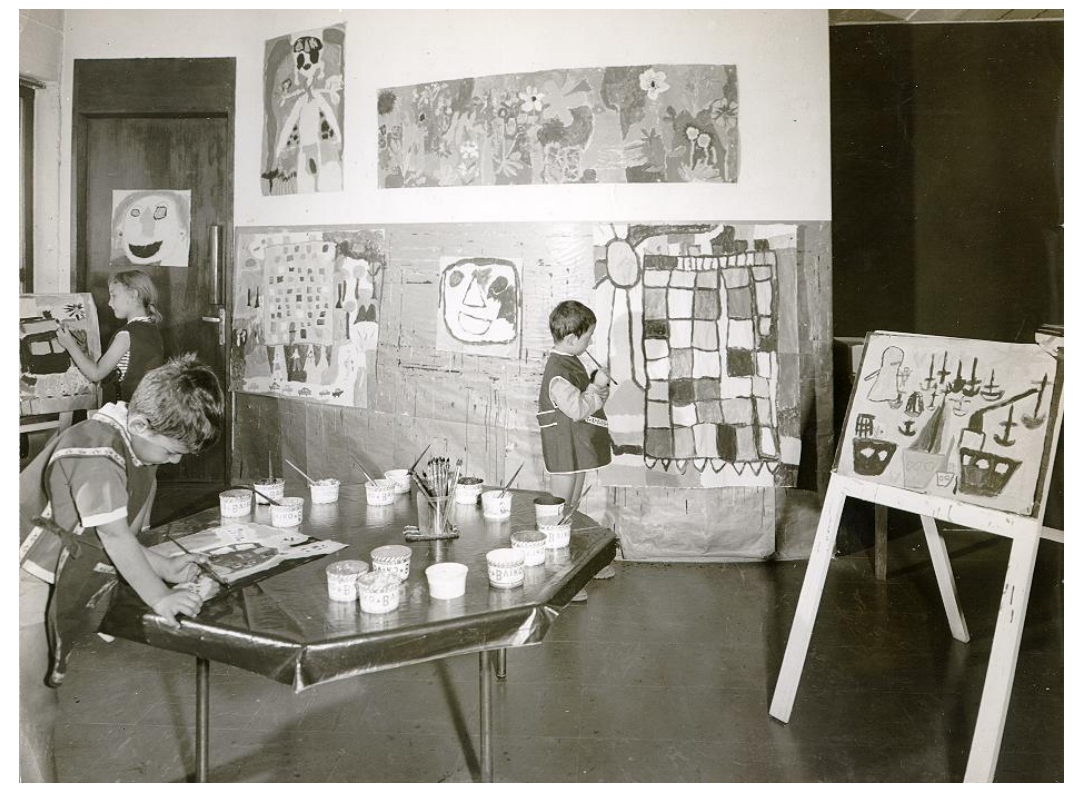

21. Dibujos sobre la pared ondulada del nivel 17. Toit-terrasse 17. (FLC L1-11 75) CFLC-ADAGP

\footnotetext{
30 "Je trouve à mon retour de voyage une série de photographies montrant les enfants sur la toiture de l’Unité Michelet.... La joie inscrite sur la visage des enfants est précisément la meilleure réponse que nous puissions donner aux critiques imbéciles." Carta de Le Corbusier a Lilette Ougier (Ripert, N.D.E) del 17/04/1953 FLC.

${ }^{31}$ Carta de Lilette Ougier (Ripert, N.D.E) a Le Corbusier del 27/10/1954 (FLC O2-4-21).
} 
Entre sus tareas diarias los niños pintan y modelan. El niño piensa haciendo y hace pensando, tal como afirmaba Freinet; Modelando al aire libre, en la terraza cuando el tiempo lo permite, sobre los bancos de hormigón y piedra. Las puertas pivotantes (fig 22) son elementos de entretenimiento para el niño y además permiten configurar los espacios de la escuela; "les petits peignent beaucoup, souvent avec des broches, des grandes papiers, et de la peinture Matroil. Ils vivent dans cette école colorée, dans leur appartement coloré, ils vivent dans le soleil sur le toit, sur la loggia, ce soleil que entre à flots pour les grands ports fénétres, par tous les plans de verre." 32

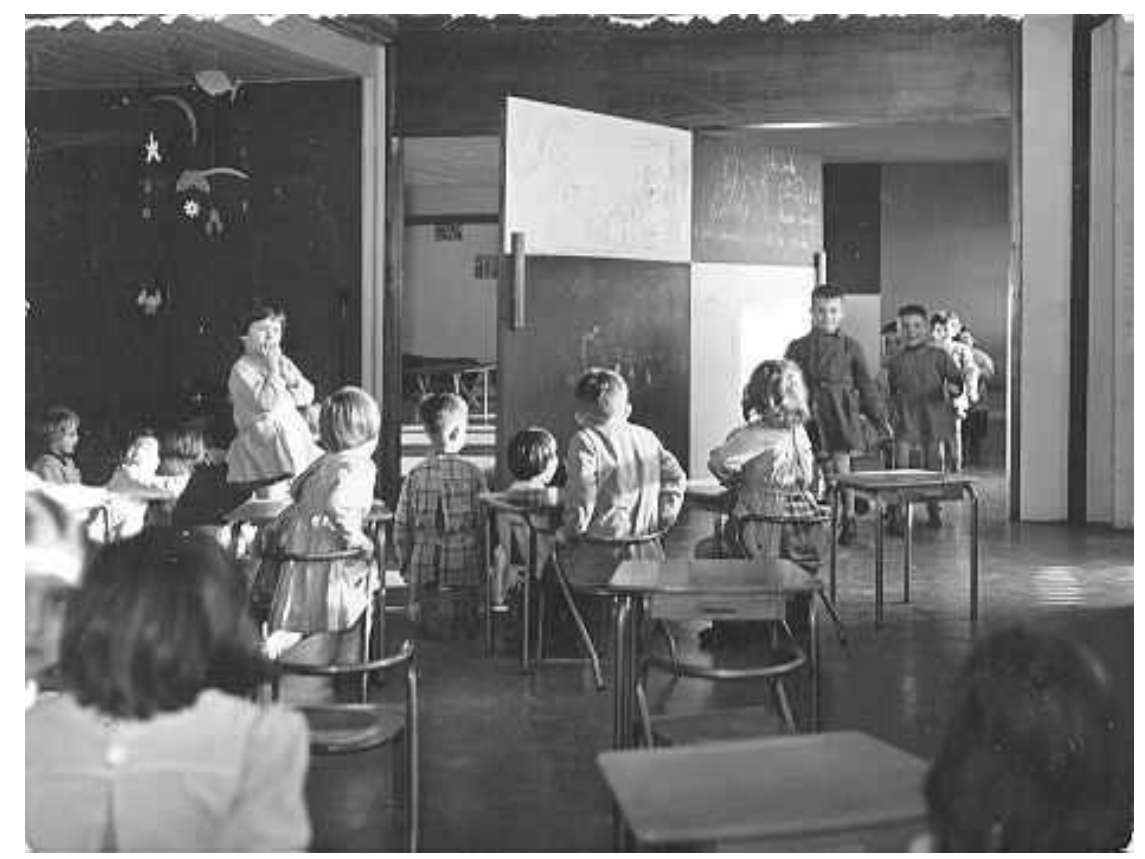

22. Puerta pivotante. Niveau 17. (FLC L1-11 71) @FLC-ADAGP

La rampa de hormigón (fig 23) que comunica la planta inferior con la cubierta se convierte en otro elemento lúdico para los niños. El plano inclinado emerge de la sala de juegos en la planta 17 y es una brecha que atraviesa el suelo hacia el cielo, las nubes, el sol y las montañas. Esta misma rampa sigue ascendiendo hacia la crèche (fig 24) construida sobre la balsa de agua en la cubierta. Ascienden por ella para realizar ejercicio físico en la terraza, juegan en el túnel, escalan sobre las rocas artificiales y se dejan deslizar sobre el plano inclinado. Se bañan en la piscina, bajan al parque, descienden sobre la hierba, recogen flores y construyen cabañas. ${ }^{33}$ Tal como describe Lilette Ripert, la escuela está, ante todo, adaptada al niño. " "Il faut faire l'expérience de monter sur la terrasse pour comprendre la vie d'un gosse, et là c'est l'ancien instituteur qui parle. Comprendre la vie d'un gosse quand il est dans la cour de récréation sur le toit-terrasse; en pensant que ce gosse mesure 75 à 80 centimètres et qu'il y a des murs en béton à un mètre vingt. Quelle est sa vision? Il n'y a que le ciel, il ne voit même pas la nature autour. "35

\footnotetext{
${ }^{32}$ Lilette Ripert, "La peinture", manuscrito, s.d (FLC B1-2 53)

${ }^{33}$ Le Corbusier, Les Maternelles vous parlent, op. cit., p. 59

${ }^{34}$ Le Corbusier, Op. cit., p. 60

${ }^{35}$ Entrevista del 22 noviembre 2002. Noél Jouenne, Le Corbusier comme compétence. Pratiques sociales dans I'Unité d'Habitation Le Corbusier de Firminy, p.112.
} 

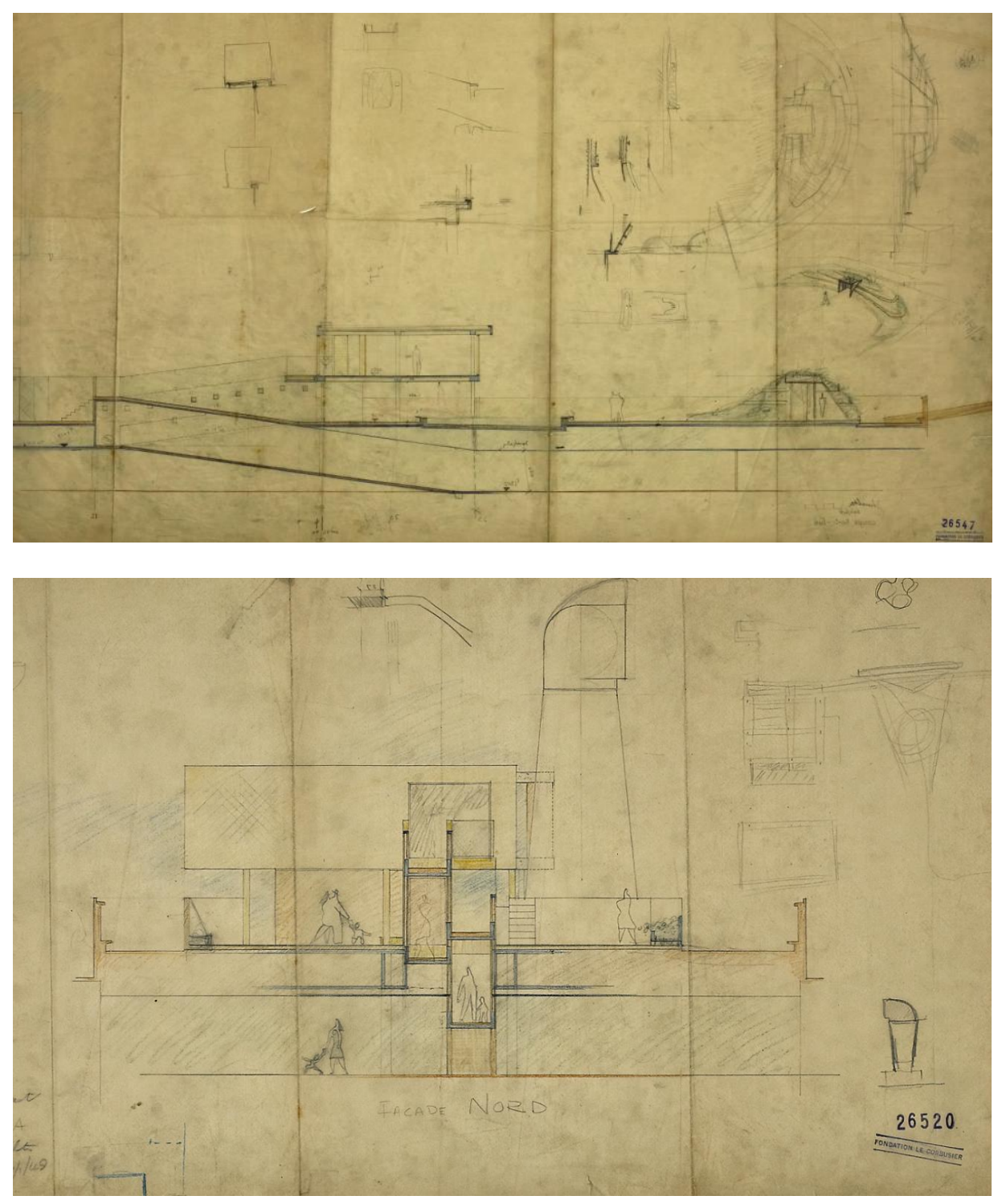

23. Coupe Nord-Sud. Serralta. 20/11/1949 (FLC 26547) CFLC-ADAGP

24. Coupe du rampe. Niveau 18. Serralta. 25/01/1949 (FLC 26520) (FLC-ADAGP

La gran capacidad de imaginación que tienen los niños les permite interpretar lo que la escuela les ofrece para adaptarlo a sus necesidades. Los techos, de $2.26 \mathrm{~m}$ de altura crean esa intimidad cálida que reina en la escuela. Situada en pleno cielo, reúne todas las condiciones para tener una vida feliz. ${ }^{36}$ Muchos visitantes criticaban la "desnudez de la escuela”, a lo que Lilette Ripert responde: “ Elle est nue, mais le soleil, le mistral, la mer, les couleurs, les dessins des gosses, la joie des gosses, parent sa nudité." ${ }^{37}$ La creación de "clubs d'enfant" incrementó la cantidad de actividades en la escuela, "nous avons tout de même commencé et avons déjà un club de théâtre spontané-une talle avec tables de ping-pong électrophone. Je vais essayer de toucher " l'Inspection des sports" pour avoir matériel et subvention-nous allons avoir aussi séance de cinéma et de télévision le jeudi. "38

\footnotetext{
${ }^{36}$ Le Corbusier, Les Maternelles vous parlent, op. cit., p. 60

${ }^{37}$ Le Corbusier, Op. cit., p. 60

${ }^{38}$ Carta de Lilette Ougier (Ripert, N.D.E) a Le Corbusier del 31/12/1954 (FLC B1-2 54)
} 


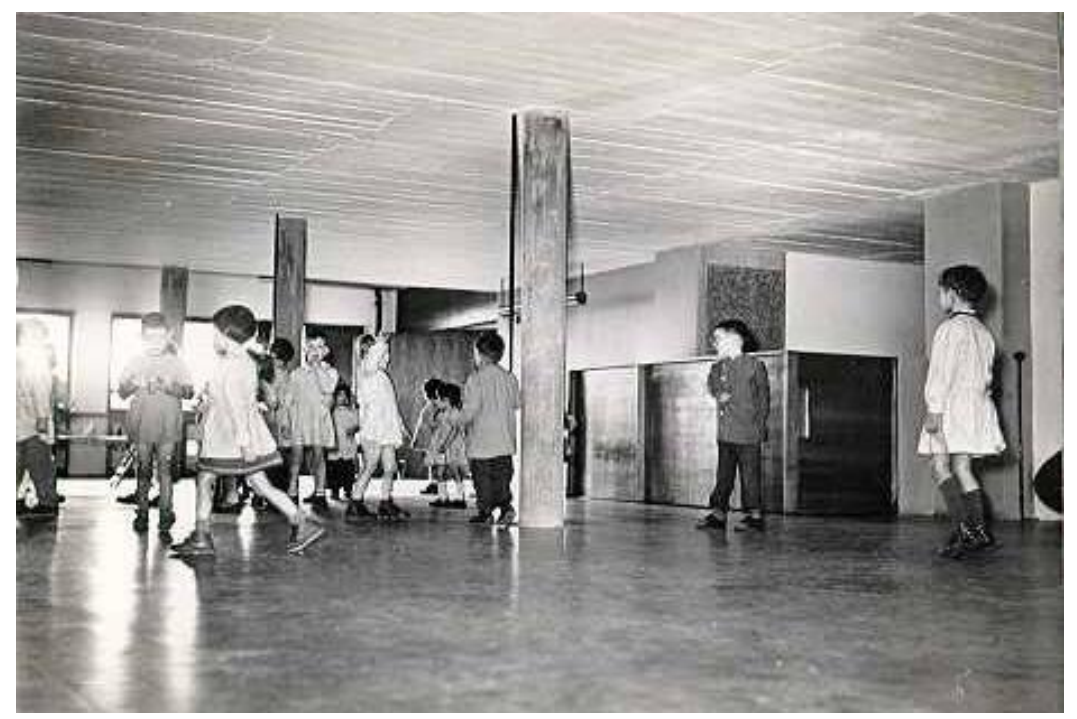

25. La salle de jeux. (FLC L1-11 65) @FLC-ADAGP

El suelo de Dalami, la salle de jeux (fig 25), su luz y su organización abierta permiten una relación estrecha y comunicativa entre todos los lugares de la escuela. Los niños se desplazan de un lugar a otro y se apropian del espacio, lo hacen suyo. El mobiliario es ligero y los niños tienen la libertad de desplazarlo. Sobre las mesas cuadradas hacían el modelado y pintaban las cerámicas, e incluso durante un tiempo se estuvo decidiendo cómo se pintaban los muebles, y Le Corbusier le aconsejaría que solo pintara las patas y dejara los tableros y las sillas blancas (como un niño más, siempre jugando).

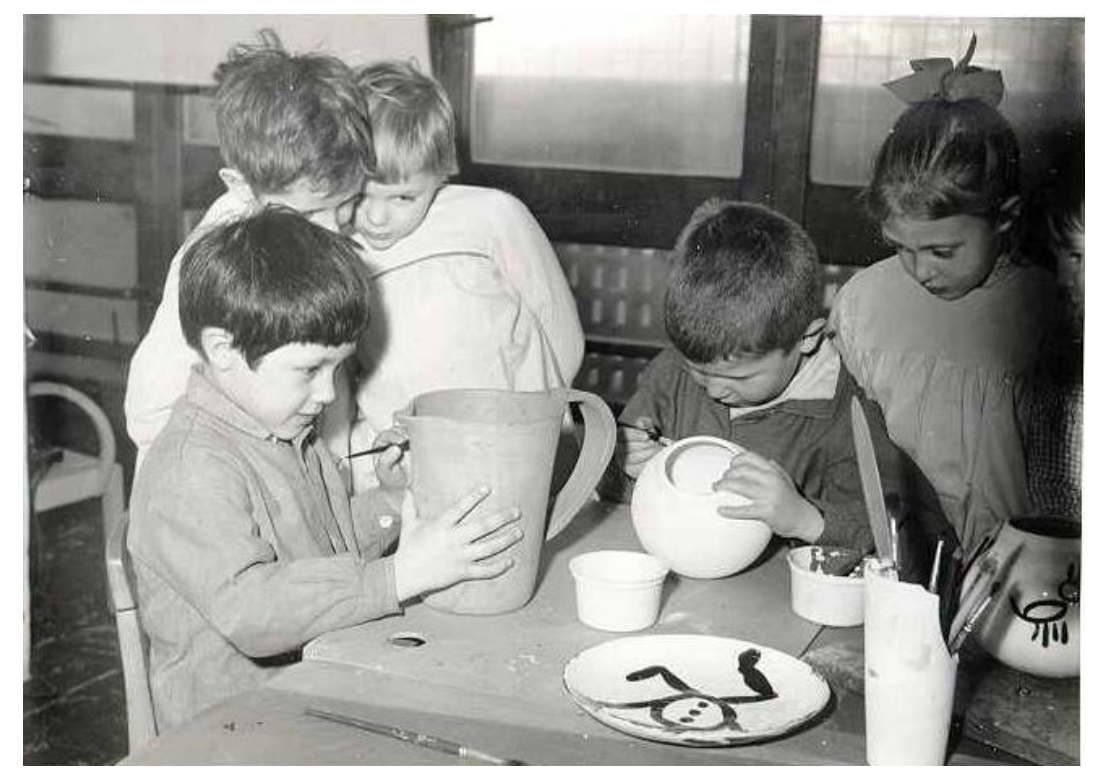

26. Los niños pintando. (FLC L1-11 85) @FLC-ADAGP 
"Voici la dernière utilisation du plan incliné. Je ne sais si vous avez prène qu'il servirait un jour de piste de luge! Les enfants et moi nous sommes bien régalés. Les collines artificielles du Parc ont aussi magnifiquement servi comme piste de ski. Il y a aussi des photos sensationnelles. ${ }^{, 39}$ De nuevo, se demuestra la utilización de estos elementos artificiales como elementos de juego.

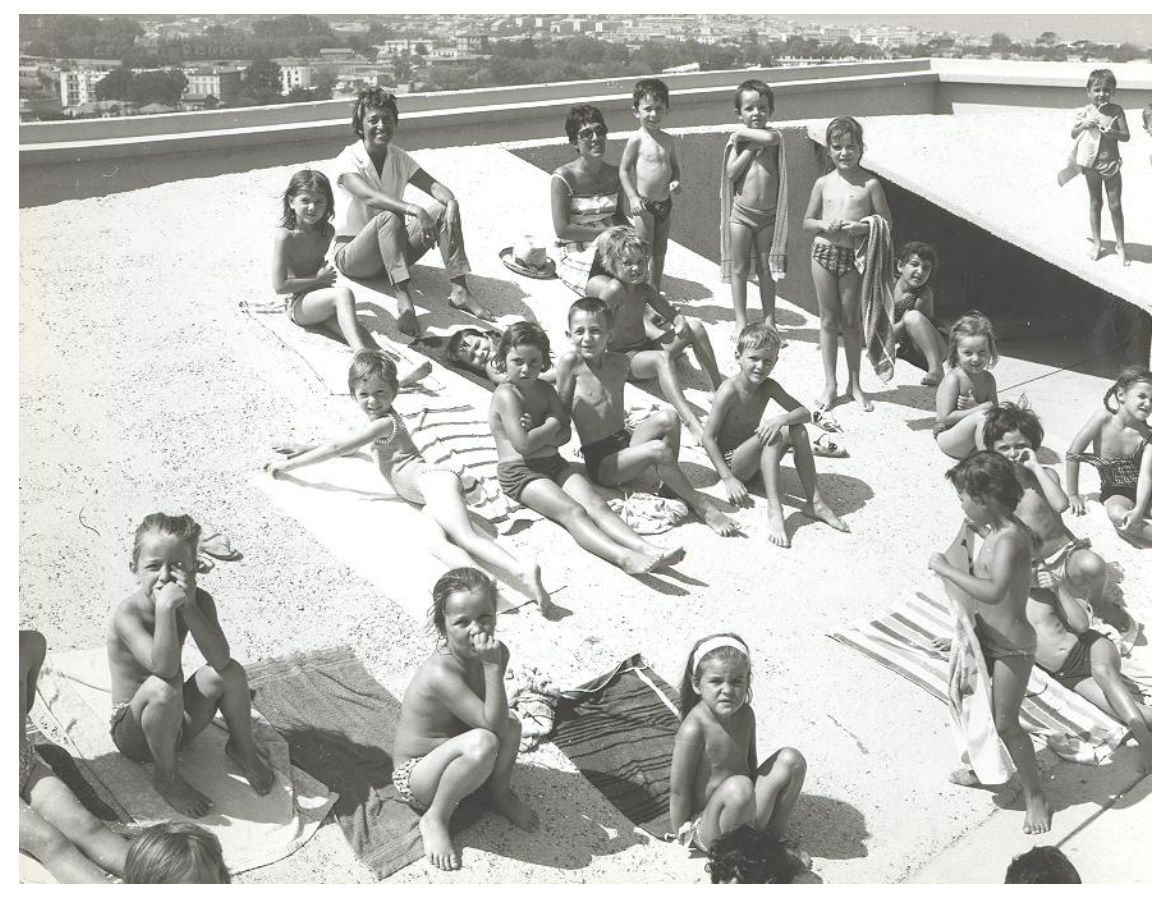

27. El plano inclinado. (FLC L1-11 38) CFLC-ADAGP

\section{Les Maternelles vous parlent}

Le Corbusier reclama continuamente fotografías, escritos y documentación sobre lo que ocurría en la escuela. En 1955 redacta el índice para los cuadernos que recoge el trabajo recopilado por Lilette Ripert y realizado por los niños, documentos, anotaciones escritas por la directora, por los niños y por los visitantes...; "LES CARNETS DE LA RECHERCHE PATIENTE No2. MATERNELLE MICHELET. La Maternelle de Marseille Michelet vous parlent".

"Pour les documents graphiques il me manque des vues qui donnent une notion claire des nouvelles classes dans leur ensemble et avec la foule des gosses et les vues sur la mer ou sur la montagne. Il faut que ces sacrés photographes comprennent un peu qu'ils doivent exprimer la vie." 40

\footnotetext{
${ }^{39}$ Carta de Lilette Ougier (Ripert, N.D.E) a Le Corbusier del 19/01/1960 (FLC O2-4 91)

${ }^{40}$ Carta de Le Corbusier a Lilette Ougier (Ripert, N.D.E) del 07/10/1955 (FLC E2-17 368)
} 


\section{Les Maternelles. Michelet-Marseille, la escuela pionera}

En 1956 Lilette Ripert comienza sus relaciones con directoras o los responsables del resto de Maternelles. Será ella quien aconsejará sobre algunos aspectos a sus responsables. ${ }^{41} \mathrm{Al}$ mismo tiempo Le Corbusier anima a Lilette Ripert a continuar con sus trabajo de redacción para el "Carnet de la Recherche Patiente". "Ne vous croyez pas abandonée; loin da là. Donnez donc un peu de vos nouvelles. ${ }^{, 42}$ El 29 de mayo de 1956 le informa de que van a comenzar la impresión del libro de las dos Maternelles: Marseille y Rezé, y le pide que le envíe "des photographies charmantes et instructives avec les fêtes-kermesses sur le toit et complétez avec vos textes." "43 Lilette Ripert le recuerda que ya tiene todo un álbum completo de fotos, "ainsi que des grandissements de Kermesse (que j'avais confis a Masson) j'envoie tout ce que je peux, tout qui me reste choisiez, ainsi que les textes. ${ }^{, 44}$ Heilbuth, la secretaria de Le Corbusier, "Il m'a chargée de vous dire sans tarder davantage que votre envoi du 31 mai 56 l'a vivement intéressé. Tout est très bien." ${ }^{45}$

La directora no cesa en comunicar a Le Corbusier lo felices que son en el escuela, tanto ella como los niños. "Nous pensons souvent a vous dans notre école. Les enfants toujours nombreux, toujours heureux, continuent à peindre, à danser, à faire du théâtre spontané, à s'épanouir à l'école es sur le toir ."46

Para la escuela de Briey, André Maissonier escribe a Madame Ougier con algunas particularidades; "L'école ne pourra pas occuper toute la surface de la terrasse, il y aura une piste sur le pourtour et une grande esplanade du côté Nord pour récréations, ou fêtes. Elle aurait deux niveaux si tout le programme ne pouvait tenir sur un seul... Nous aurons toujours: petite piscine, jeux en béton et jardinets. ${ }^{47}$

Será el 9 junio de 1961 cuando el alcalde de Firminy, Claude Petit, se dirija a Lilette Ripert solicitando información para realizar una visita ya que tienen la intención de construir una escuela dentro de la línea de la de Michelet-Marseille. ${ }^{48}$ Una década después de la inauguración del centro, en 1963 Lilette Ripert sigue agradeciéndole a Le Corbusier la satisfacción por haber enseñado en Michelet-Marseille. "Voici dux fotos prises sur le toit il y a quelques jours. Neige ou beau temps vous voyez que nous sommes toujours heureux sur votre toit. ${ }^{\text {"49 }}$ Le Corbusier ha sido durante todo este tiempo consciente de la evolución de "su escuela" igual que Lilette Ripert ha sido capaz de aprovecharla como un lugar puramente educativo. La felicita en la carta que le escribe el 3 de febrero de 1964 por los resultados de sus niños. "Je vous félicite de savoir ouvrir les yeux aux gosses que vous envoyez sur le toit de L'Unité de Marseille,- ce toit qui est unique au monde: mer et montagne, architecture ahurissante,- le tout formant un cadre digne de l'intérêt des gens intelligents dont vous êtes un modèle excellent. ${ }^{, 50}$

En 1965 l'Unité d'habitation de Marseille se declara monumento histórico, y por consiguiente queda prohibido intervenir para realizar cualquier modificación sin la autorización del ministerio y la de Le Corbusier.

\footnotetext{
41 “Je crois savoir que vous avez pris des contacts avec Rezé et que vous entendez bien." Carta de Le Corbusier a Lilette Ougier (Ripert, N.D.E) del 22/02/1956 (FLC E2-17-369)

${ }^{42}$ Carta de Le Corbusier a Lilette Ougier (Ripert, N.D.E) del 22/02/1956 (FLC E2-17-369)

${ }^{43}$ Carta de Le Corbusier a Lilette Ougier (Ripert, N.D.E) del 29/05/1956 (FLC G2-20 447)

${ }^{44}$ Carta de Lilette Ougier (Ripert, N.D.E) a Le Corbusier del 30/05/1956 (FLC O2-4-43)

${ }^{45}$ Carta de Heilbuth a Lilette Ougier (Ripert, N.D.E) del 5/06/1956 (FLC G2-20 486)

${ }^{46}$ Carta de Lilette Ougier (Ripert, N.D.E) a Le Corbusier del 1/02/1958 (FLC O2-4 61)

${ }^{47}$ Carta de A. Maisonnier a Lilette Ougier (Ripert, N.D.E) del 9/07/1959 (FLC M2-14 259)

${ }^{48}$ Carta de F.Gardien a Lilette Ougier (Ripert, N.D.E) del 9/06/1961 (FLC O2-4 104)

${ }^{49}$ Carta de Lilette Ougier (Ripert, N.D.E) a Heilbuth del 18/02/1963 (FLC O2-4 121)

${ }^{50}$ Carta de Le Corbusier a Lilette Ougier (Ripert, N.D.E) del 3/02/1964 (FLC E2-17 381)
} 
Un mes antes de su muerte, el 5 de julio 1965, Le Corbusier se dirige a Lilette Ripert;

"Il y a de quoi crever de dépit, de rage ou de désespérance quand on voit cette toiture occupée par vos gosses, et vous même, avec son bassin, ses collines artificielles, ses rampes, son "mur de la mort" et les montagnes et la mer."

"La photo montrant les gosses nus, les jambes pendantes sur les crête de ce fameux "mur de la mort", celle du bassin avec les gosses faisant trempette à cinquante mètres au dessus du rez-de-chaussés de la maison, sont des arguments étonnants, bouleversants.... „51

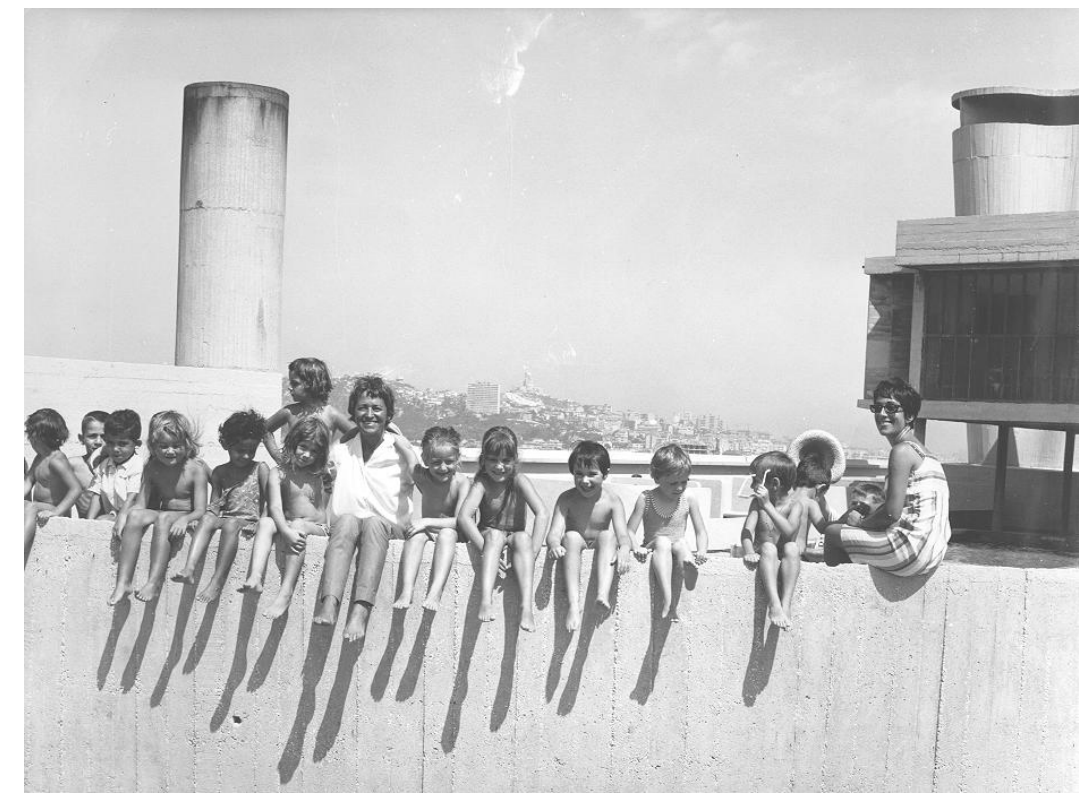

28. "Le mur de la mort". (FLC L1-11-33-001) OFLC-ADAGP

\section{El florecimiento compartido de una pedagogía más humana}

Este recorrido en el tiempo a través de unos escritos, unos dibujos y unas fotografías son el reflejo de una arquitectura construida para sus usuarios. La escuela infantil en las últimas plantas de l’Unité surge como extensión de la vivienda, como parte del recorrido diario del niño y se convierte en un lugar de encuentro abierto a infinitas posibilidades. La propuesta arquitectónica de Le Corbusier constituye el escenario sobre el cual Lilette Ripert aplica el sistema educativo basado en las teorías pedagógicas de Célestin Freinet. El funcionamiento admirable de la escuela ha sido fruto de la complicidad de Le Corbusier y Lilette Ripert meses antes de su ejecución y a lo largo de los primeros años de enseñanza.

Su funcionamiento, bajo la dirección de Lilette Ripert, supuso un periodo muy exitoso en el aprendizaje de los niños, habiendo entendido y aprovechando las instalaciones proyectadas para el desarrollo de las actividades. Su disposición de plan abierto, parcialmente al aire libre, favorece la aplicación de los principios pedagógicos de Freinet: el trabajo en equipo, el de prueba y error experimental y en especial el "método natural" o de aprendizaje auténtico utilizando las experiencias de los niños.

\footnotetext{
${ }^{51}$ Carta de Le Corbusier a Lilette Ougier (Ripert, N.D.E) del 5/07/1965 (FLC E2-17 385)
} 
Aunque la intervención de Freinet fue tardía, en las primeras propuestas de Le Corbusier es evidente su intención de construir una escuela muy abierta alejada de los planteamientos tradicionales, y que potencie la creatividad de los niños que la habitan. El enorme interés mostrado por Le Corbusier en los años de funcionamiento de l'école es una lección que demuestra que la arquitectura no es únicamente la ideación solitaria de un lugar y su entrega una vez construido, sino que lo enriquecedor es el proceso mismo y las interacciones que inevitablemente se producen entre todos los actores (constructores, directora, niños, compañeros, instituciones...); pues tienen también una gran capacidad educadora para la sociedad como conjunto y para los arquitectos mismos.

En definitiva, este viaje al interior del tiempo, hacía un pasado no muy lejano, demuestra sin duda la gran capacidad de l'école de dar una respuesta a un sistema educativo concreto. Después de varias propuestas y tras la relación con Lilette Ripert, el proyecto se desarrolló en paralelo a las teorías pedagógicas que la directora quería implantar. Las diversas actividades que se desarrollaron en la escuela han reflejado la flexibilidad de los espacios y su capacidad de adaptarse y ampliarse. Este trabajo en equipo, las conversaciones y el intercambio de ideas entre disciplinas ha sido el motor de este largo proceso. Los recursos espaciales empleados por Le Corbusier son vitales, pero es la correspondencia, los documentos y las fotografías que hablan de la relación mantenida entre Le Corbusier y Lilette Ripert los que manifiestan el mayor logro de la escuela: el florecimiento compartido de una pedagogía más humana.

\section{Procedencia de las imágenes}

Fondation Le Corbusier.

\section{Bibliografía}

Benton, Tim. Marseille: Unité d'habitation or The company of clouds, he sky, os the stars. In: Cohen, JeanLouis ed. Le Corbusier: an Atlas of Modern Landscapes, 2013, New York: Museum of Modern Art.

Freinet, Céléstin. L'éducation du travail. París: Editions Ophrys, 1949.

Le Corbusier. Les Maternelles vous parlent. Paris: Ed. Gonthier, 1968.

Sbriglio, Jacques. Le Corbusier: L'Unité d'habitation de Marseille. Ed. Birkhauser Verlag AG, 2004.

Stanislaus, Von Moos. Machine and nature: Notes a propos de l'Unité d'habitation de Marseille," in Claude Prelorenzo, ed., Le Corbusier: La Nature 1991: Paris Éditions de La Villette, 2004.

Archivo: Fondation Le Corbusier. 